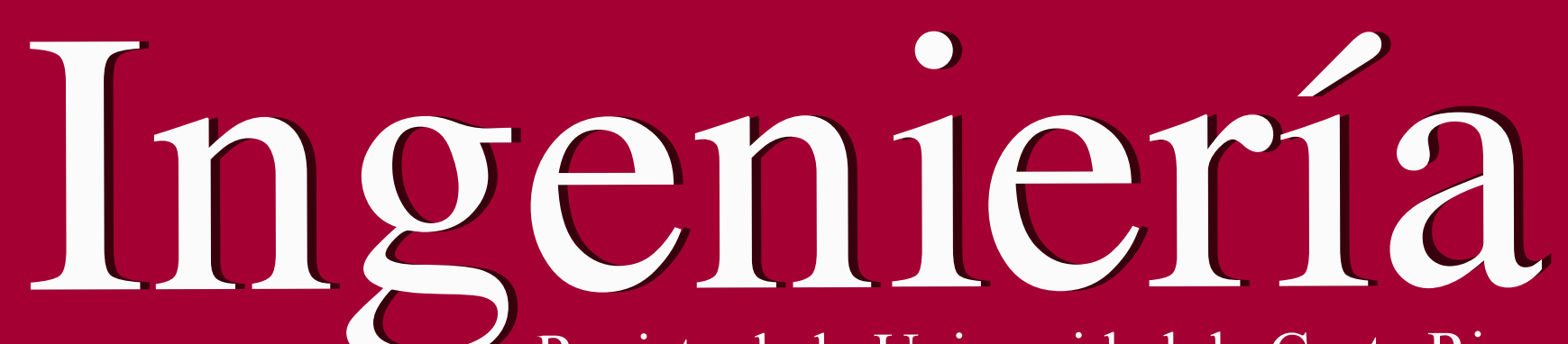

Revista de la Universidad de Costa Rica JULIO / DICIEMBRE 2020 - VOLUMEN 30 (2)

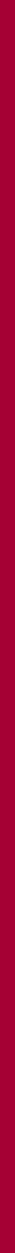




\title{
Arreglos fotovoltaicos inteligentes con modelo LFSR-reconfigurable
}

\author{
Cecilia Esperanza Sandoval-Ruiz, \\ Profesora Titular de Postgrado de Ingeniería \\ Universidad de Carabobo, Carabobo, Venezuela \\ cesandova@gmail.com \\ ORCID: https://orcid.org/0000-0001-5980-292X
}

Intelligent Photovoltaic Arrays with LFSR-Reconfigurable Model

Recibido: 31 de noviembre 2019

Aceptado: 26 de marzo 2020

\section{Resumen}

En esta investigación se presenta un modelo de tecnología fotovoltaica reconfigurable para la investigación y el desarrollo de arreglos inteligentes. El estudio comprende una revisión de técnicas de síntesis de celdas fotoelectroquímica, factores de optimización en arreglos fotovoltaicos y electrónica para la definición de capas funcionales de separación espectral, concentración solar, conversión fotoeléctrica, registro de energía, mecanismos de seguimiento solar y recuperación de calor regenerativo, adaptados a través de redes neuronales aplicadas. Se establecieron criterios para la configuración de los dispositivos fotovoltaicos inteligentes IPVD, soportados por tecnología FPGA. El método de modelado se basa en identificación de correspondencia de las estructuras fotovoltaicas con la estructura LFSR: concatenación de aportes y realimentación de energía en el marco de sistemas regenerativos. Para la formulación de la composición y síntesis, se describió la ANN fractal en VHDL y se reportó la síntesis de la estructura circuital. Se obtiene como resultado un modelo para SFV, reporte de mejora por seguimiento en dos ejes en el orden $\sim 10 \%$ y los códigos de configuración del control electrónico. Todo esto permite aportar en la migración hacia nuevas tecnologías y modelos sostenibles de la matriz energética con estimación de eficiencia e impacto ambiental. Se obtiene como conclusión un concepto tecnológico que se basa en un modelo fractal aplicado al diseño del convertidor fotovoltaico generalizado, coeficientes de aporte concatenado y recuperadores para realimentación de energía. Aplicando el principio de reconfiguración dinámica estructural a fin de establecer la composición tándem dentro de un modelo circular.

\section{Palabras clave:}

Ingeniería de la Energía Solar, Modelo Matemático, Circuitos Electrónicos, Semiconductores, Inteligencia Artificial

\begin{abstract}
This study presents a reconfigurable photovoltaic technology model for research and development. The study includes a review of photo-electrochemical cell synthesis techniques, which are optimization factors in photovoltaic arrays and electronics for the definition of functional layers of spectral separation, solar concentration, photoelectric conversion, energy recording, solar monitoring mechanisms and recovery of regenerative heat, adapted through applied neural networks. Criteria were established for the configuration of IPVDs smart photovoltaic devices supported by FPGA technology. The modeling method is based on the
\end{abstract}


identification of the correspondence of the photovoltaic structures with the LFSR structure, which means the concatenation of contributions and energy feedback within the framework of regenerative systems. For the formulation of the composition and synthesis, the fractal ANN in VHDL was described, and the synthesis of the circuit structure was reported. The results are obtained as a model for SFV, showing an improvement report by monitoring in two axes in the order $\sim 10 \%$ and the configuration codes of the electronic control. All this makes it possible to contribute to the migration towards new technologies and sustainable models of the energy matrix with estimates of efficiency and environmental impact. In conclusion, a technological concept is obtained, which is based on a fractal model applied to the design of the generalized photovoltaic converter, concatenated contribution coefficients and recuperators for energy feedback. It is applied the principle of dynamic structural reconfiguration in order to establish the tandem composition within a circular model.

\section{Keywords:}

Solar power engineering, mathematic models, Electronic circuits, Semiconductors, Artificial intelligence 


\section{INTRODUCCIÓN}

Actualmente muchas investigaciones se centran en la eficiencia de los paneles fotovoltaicos (FV), medida en laboratorio con estimaciones teórico-prácticas a partir del uso de materiales con propiedades fotoeléctricas para aprovechar la irradiancia recibida sobre la superficie de estudio. Los parques solares han sido pensados como espacios para contrastar la capacidad de conversión de diversas tecnologías. En este orden de ideas, se propone el diseño de una plataforma portátil de investigación (Sandoval, 2016) ahora orientada a la optimización en tecnología solar fotovoltaica, aplicando redes neuronales artificiales (ANN) con el fin de estudiar el comportamiento en campo y proponer nuevas configuraciones de paneles FV. Una recopilación de conceptos en tecnología solar es presentada en González (2015), la cual enuncia diversos métodos para optimizar la eficiencia del campo solar fotovoltaico en situaciones de irradiación no uniforme. Estos aplican en la forma de interconectar los módulos en el arreglo FV en configuración TCT (Total-Cross-Tied), BL (Bridge Linked) y HC (Honey-Comb) por su incidencia en la eficiencia del sistema y en las características técnicas del panel fotovoltaico definidas por las capas componentes. Una de ellas, la capa antirreflejante ARC, presenta propiedades particulares en relación con el espesor diseñado de acuerdo con la longitud de onda de la radiación que se requiere maximizar y toma en cuenta características de la onda recibida y el índice de radiación del material para los ajustes en su composición. De manera que se puede establecer el comportamiento esperado a través de un modelo matemático que relaciona coeficiente de absorción del material $\alpha$ y conversión e interacción entre capas para optimizar el rendimiento de la célula fotovoltaica.

En la tecnología fotovoltaica se habla de tres generaciones: células de silicio (alta eficiencia y altos costos), tecnología de película fina (disminuye costos y eficiencia menor) y tecnología conceptual (alta eficiencia en estudio y menor costo). Entre las técnicas de optimización se tiene el ampliar el rango espectral que puede absorber la célula (células multi-unión, células con bandas intermedias, células con puntos cuánticos), reducir las pérdidas por termalización (células hot-carriers, varios pares electrón-hueco por fotón), adaptar el espectro solar al material receptor (conversión up / down, células termo-fotovoltaicas y termo-fotónicas) a través de capas superpuestas al módulo FV y aumentar la cantidad de luz incidente (concentración fotovoltaica). Al momento de diseñar un modelo teórico de integración tecnológica para sistemas fotovoltaicos (SFV), se deben considerar tópicos referentes a ciencia de materiales (Venneri \& Borgia, 2019), modelos de hardware reconfigurable (Sandoval, 2019a) y control de convertidores solares reconfigurables (RSC) para fotovoltaica (Kim, Parkhideh, Bongers \& Gao, 2012). Esto con el propósito de optimizar funcionalidades físicas a partir del ordenamiento de estructuras (en relación con los niveles de conversión y fases del material) para la adaptación de sus propiedades y comportamiento a los requerimientos de diseño. Se considera para ello el modelado a partir del principio fotosintético y procesos de biología molecular de activación e inhibición de fotones para la conversión y almacenamiento de energía. En investigaciones sobre pigmentos orgánicos (a partir de plantas, flores y algas) se establece las propiedades de selectividad en conversión de fotones del espectro de luz visible y su aplicación en la biotecnología ambiental (Navarro, 2015). En Ruiz (2014) se plantean compuertas lógicas inhibit, and, or moleculares en transferencia electrónica foto-inducida y transferencia de 
energía para aplicaciones en SFV. Establecer una correspondencia entre las operaciones lógicas del LFSR (Lineal Feedback Shift Register), selector de señales xor, inhibit, resulta una herramienta de interés para el diseño de electrónica molecular aplicada a la implementación de celdas solares inspiradas en fotorreacciones (en plantas y semillas) y biología molecular.

De esta manera, se plantea la investigación para el manejo de etapas de optimización como lentes ópticos, concentradores selectivos de radiación solar, capas de semiconductores fotovoltaicos adaptativos, capas componentes intercambiables o manejados por habilitadores, dieléctricos configurables, pigmentos orgánicos y capacidad biodegradable programada por campo eléctrico, es decir, un conjunto de propiedades de las capas y materiales que puedan ser definidos por software. Esto permitirá la formulación de compuestos fotoeléctricos in situ sobre los paneles implementados con base en la identificación de la estructura LFSR que se corresponde, de forma fractal, en la configuración de materiales y operadores de sensibilización porcentual con realimentación lineal y en la estructuración de capas funcionales concatenadas con realimentación de fotones en el mecanismo de arreglos fotovoltaicos. En Valero Delgado (2019) se expone los retos en materia prima, destacando la necesidad que los científicos se centren en el potencial de ahorro de materiales y energía y la reducción de emisiones contaminantes desde una visión holística de los ciclos de vida y las cadenas de reciclaje de diseño ecoeficiente, des-ensamblaje y logística inversa. Un enfoque en investigación de materiales reconfigurables en fotovoltaica se perfila como una herramienta para la integración de un modelo circular en el sector energético solar.

Todo esto lleva a plantear un modelo teórico de fotovoltaica reconfigurable que permita la adaptación de parámetros intrínsecos del material, extrapolando conceptos de reconfiguración electrónica a través del manejo avanzado de datos con ANN con el fin de lograr un mejor rendimiento del conjunto en configuración tándem. En investigaciones previas (Sandoval, 2018a) se han planteado dispositivos inteligentes, donde se definen sistemas reconfigurables de convertidores de energías renovables (ERNC) con un arreglo con múltiples etapas de convertidores (aporte en función de la eficiencia de conversión), elementos de almacenamiento y realimentación. La operación del arreglo propuesto comprende, en régimen transitorio, el aporte de energías renovables (que dependen de las condiciones climáticas) y la realimentación al sistema de energía almacenada (para reconvertirla en energía eléctrica) en un ciclo regenerativo. Con estos criterios, se estudian los avances en materia de fotovoltaica emergente.

En Einzinger et al. (2019) se expone el concepto de fisión simple como una reacción de los fotones ante una banda intermedia de material que permite una ganancia en la conversión de energía, llevando el límite teórico hasta un 35 \%. En Martínez, Gallardo y Ríos (2016) se plantean materiales alternativos para dispositivos de células solares sensibilizadas por colorante (Dye Sensitized Solar Cells o DSSC), donde se contrastan parámetros como la conductividad iónica y estabilidad entre los electrolitos sólidos-líquidos. En Flores (2014) se han caracterizado celdas solares sensibilizadas con pigmentos naturales tales como curcumina, flor de Jamaica, entre otros, lo que representa alternativas para DSSC con componentes ecológicos. En Reyes-Tolosa (2012) se presenta un estudio de las alternativas de formación de capas en células fotovoltaicas. Se afirma que las propiedades de los materiales y el control de la materia a nano-escala inciden en su comportamiento. 
Este hecho se debe a que los materiales no se comportan igual en sus diferentes escalas, es decir, las características ópticas, eléctricas, entre otras, pueden verse modificadas dependiendo de como ha sido constituido el material. Así, los semiconductores a partir de óxidos metálicos nanoestructurados tienen buenas propiedades fotovoltaicas.

En la comparación de las tecnologías fotovoltaicas, se aplica el límite Shockley-Queisser (33.7 \% sin concentración), el cual describe la máxima eficiencia de conversión de energía solar alcanzable para un material en particular y se basa en el principio del equilibrio detallado entre el flujo de fotones en un dispositivo y el flujo de partículas (fotones o electrones) fuera de ese dispositivo, el cual no aplica a tecnologías con múltiples capas. Por su parte, las células solares nanoestructuradas representan una clase novedosa de dispositivos FV de unión simple, ya que éstas tienen una eficiencia máxima teórica de $42 \%$ dentro del límite con concentración óptica, por lo que representan una ruta alternativa de alta eficiencia (Xu, Gong \& Munday, 2015).

En Amorós-Pérez et al. (2019) se documentan las propiedades de los fotocatalizadores donde se menciona el óxido de Titanio $\left(\mathrm{TiO}_{2}\right)$. Estos materiales presentan reacciones fotosintéticas que permiten la degradación de ciertos compuestos (absorción de $\mathrm{CO}_{2}$ ) para el proceso de descontaminación o bioremediación. Asimismo, en Camargo-Silva, Muñoz-Prieto, Vera-Graziano y Gomez-Pachón (2017) se presenta la aplicación de materiales semiconductores (óxidos metálicos) con propiedades fotoeléctricas para el almacenamiento de energía por su potencial en ERNC. Todas estas formulaciones resultan de interés para la integración de capas multifuncionales en las celdas de conversión. El proceso de fabricación de los paneles FV está relacionado con un alto consumo de energía, el cual es equivalente a la energía producida en los primeros años de vida útil del dispositivo convertidor. Esto es un indicador de la necesidad de diseñar procesos de fabricación más eficientes y sostenibles.

De igual manera, en operación se debe considerar el reciclaje de energía, aprovechando las formas de energía residual y todos los componentes del espectro electromagnético en la obtención de energía eléctrica. Una alternativa es la integración de tecnología de almacenamiento en una capa del arreglo FV a nivel de manejo de transportadores de energía lumínica (plasmones: plasma + fotones), retardo $\tau$ asociado al desplazamiento de intercapas, concentradores (en términos de separación espectral y reflexión interna de fotones), o eléctrica en ultracondensadores (González, 2015), considerando las alternativas en registros de energía. Para aumentar el rendimiento de las celdas fotovoltaicas, se cuenta con arreglos que buscan aumentar la captación de fotones en el espectro óptico de luz visible, así como aumentar la captación de electrones en la etapa de conversión con el fin de alcanzar una mayor potencia de energía eléctrica convertida. En el caso de las células PERC, éstas integran una lámina aislante para aprovechar los fotones incidentes en su totalidad, lo que hace que tengan mejor rendimiento fuera de las horas de sol pico HSP o en ambientes nublados.

Las células fotoelectroquímicas se clasifican en: regenerativas, conversión directa a energía eléctrica (sin cambios químicos), y fotosintéticas, producción simultánea de energía eléctrica y una sustancia de interés por reacción química reducción/oxidación (redox). En Alarcón et al. (2014) se discute la optimización de materiales semiconductores para aplicaciones fotovoltaicas a través de la preparación electroquímica de capas nanoestructuradas por la posibilidad del ajuste de parámetros 
característicos del material y el aumento de la eficiencia del convertidor de energía solar a eléctrica, siendo de interés para la presenta investigación las técnicas simplificadas de bajo consumo de energía que puedan ser implementadas de forma portátil. Las celdas solares fotoelectroquímicas dan lugar a una gran cantidad de investigaciones sobre la búsqueda de películas delgadas policristalinas, semiconductores binarios optimizando la banda energética o Band Gap entre sus propiedades físicas. A partir de estos avances, se considera la síntesis electroquímica de semiconductores con propiedades fotoeléctricas óptimas como alternativa para instalaciones fotovoltaicas adaptativas.

En Formentín (2013) se presentan las características electrónicas de los dispositivos fotovoltaicos de células de Grätzel, el cual incorpora una variación a las células DCCS a través de un material nanoestructurado semiconductor mesoporoso y cuya función es aumentar la superficie de anclaje y permitir mayores concentraciones de colorante fotosensibilizador que resulta en una cosecha más eficiente de la radiación incidente. Los resultados experimentales, aplicando colorantes orgánicos y el uso de nanopartículas semiconductoras de $\mathrm{TiO}_{2}$ reportan valores entre $5.8-11.5 \%$ de eficiencia. Dentro de la categoría de tecnologías emergentes, las celdas solares de tipo perovskita (PSC), estructuras minerales de la fórmula química $\mathrm{ABX}_{3}$, han llamado la atención de la comunidad científica por los niveles de eficiencia alcanzados. En Gutiérrez, Quijano, Gutiérrez y Cervantes (2018) se presenta un análisis detallado de la estructura perovskitas (híbridas y completamente inorgánicas), técnicas de optimización y estabilidad en el medio ambiente. Las perovskitas híbridas presentan bajo costo y alta eficiencia en el caso de la tecnología de película delgada en el orden de $21 \%$ (Khalaji, Bakhodaa, Saidurbc \& Hanaeia, 2018) y con características como alto coeficiente de absorción, amplio rango espectral y longitud de difusión. Sin embargo, estas presentan baja estabilidad, por lo que presentan degradación para ciertas condiciones ambientales. Actualmente, la investigación sobre PSC se centra principalmente en formas de obtener alta eficiencia y estabilidad a través de diferentes métodos de fabricación e ingeniería de materiales. Se consideran semiconductores del grupo III y V en la tabla periódica y las de nueva generación las perovskitas híbridas, CZTS, entre otros. Para conseguir los PSC de alto rendimiento, se debe tener control de la morfología, la estructura cristalina y las técnicas de construcción (Pérez, Yasmin, Gómez \& Vera López, 2018). Estas técnicas pueden ser aplicadas para la configuración dinámica del arreglo de la celda solar.

Recientes investigaciones reportan una eficiencia de conversión máxima teórica del $38.7 \%$ en una célula solar tándem de perovskita de silicio en el material BaZrTiS $_{3}$, señalando que presenta alta estabilidad (Nishigaki et al., 2020). Estos materiales híbridos permiten definir una línea de investigación en materiales configurables activados a través de técnicas similares a la configuración por campo. Algunos retos corresponden a criterios de diseño como la disminución del consumo de energía durante el proceso de fabricación de los paneles solares, la sensibilización del panel con pigmentos sintetizados in situ, la simplificación de los componentes del panel fotovoltaico, la disminución de la degradación de los materiales, la reconfiguración dinámica del arreglo de celdas fotovoltaicas y capacidad regenerativa. Se incluye también la digitalización, es decir, monitoreo y teleoperación para optimización del panel PV (dedicados o multiplexados), mantenimiento ecológico (mínimo consumo de agua y procedimientos simplificados con componentes modulares), reutilización de 
componentes y programación de reciclaje de materiales y residuos no tóxicos, control selectivo de propiedades de materiales biodegradables y sistema recuperación de calor regenerativo (RCR).

Kim, Xu, Jin y Krein (2013) desarrollan un modelo considerando el conjunto de parámetros asociados al comportamiento de los módulos fotovoltaicos en función de condiciones particulares relacionadas con las condiciones nominales del panel, como se presenta en la fórmula (1):

$$
I_{P V}(G, T)=\left[I_{s c n}\left(\frac{R_{s}+R_{s h}}{R_{s h}}\right)+K_{i}\left(T-T_{n}\right)\right] \frac{G}{G_{n}}
$$

Donde la $I_{P V}$ corriente fotovoltaica, en la cual se observa aportes definidos por coeficientes característicos y que se puede interpretar como la sumatoria de pesos sinápticos del arreglo PV por la irradiancia recibida. Los parámetros están dados por $I_{s c n}$ corriente de corto circuito, $K_{i}$ coeficiente de corriente-temperatura $[\mathrm{A} / \mathrm{K}]$, resistencias $[\Omega]$. $G$ Irradiancia y $G_{n}$ la irradiancia nominal $\left[\mathrm{W} / \mathrm{m}^{2}\right]$

Una vez revisados los avances científicos en tecnologías fotovoltaicas, se observa que estos se encuentran enfocados en materiales, por lo que una línea de investigación necesaria corresponde a una configuración de estos. En la literatura no se ha encontrado un modelo basado en la estructura LFSR del ordenamiento de las capas/películas de material fotoeléctrico. En tal sentido, se considera el concepto tecnológico de fotovoltaica como reconfigurable y el modelo matemático para el soporte de formulaciones optimizadas en su implementación a través de celdas configurables de material fotovoltaico en convertidores solares por medio de la captación de fotones en distintas longitudes de onda del espectro electromagnético. Se identifica como objetivo la simplificación de los arreglos tándem, disminución de consumo de energía en fabricación y costos del material. Para ello, se aporta como alternativa el multiplexado en tiempo-espacio del conjunto porta-capas y capas optimizadas para un servicio de barrido de los módulos fotovoltaicos, instalados con un sistema de control basado en lenguaje descriptor de hardware VHDL (VHSIC-HDL).

\section{METODOLOGÍA}

El método de modelado comprende el estudio de tecnologías, capas funcionales, materiales experimentales (reportados en la literatura científica), definición de células solares híbridas e identificación de correspondencia con la estructura LFSR, para la optimización del arreglo fotovoltaico aplicando ANN en VHDL, orientado a hardware reconfigurable. Para esto, se realizó la comparación de semiconductores posicionados en el sector energético y nuevos materiales emergentes. Se contrastaron las ventajas y retos de cada una y los aportes de modelos híbridos aplicados como se resume en la tabla 1.

Es importante señalar que las diversas tecnologías estudiadas presentan una composición fija, en tanto que la tecnología LFSR propuesta está pensada para una composición adaptativa en rela-

ción con los coeficientes de optimización y habilitadores selectivos en la estructura. Se plantea así el uso de cómputo avanzado con hardware reconfigurable FPGA (Field Programmable Gate Array) 


\section{Tabla 1. Comparación de Tecnologías Fotovoltaicas}

\begin{tabular}{|c|c|c|c|c|c|c|}
\hline Clas. & $\begin{array}{l}\text { Materiales } \\
\text { fotovoltaicos }\end{array}$ & Costos & $\begin{array}{l}\text { Eficiencia } \\
\boldsymbol{\eta}\end{array}$ & $\begin{array}{l}\text { Vida Útil } \\
\text { (años) }\end{array}$ & Tecnología & Características \\
\hline \multirow{2}{*}{$\begin{array}{l}\mathrm{I} \\
\mathrm{Si}-\mathrm{c}\end{array}$} & Si Mono-cristalino & \multirow{2}{*}{ Elevado } & $16.0 \%$ & \multirow{2}{*}{$20-30$} & \multirow{2}{*}{$\begin{array}{l}\text { Silicio Cristalino } \\
\text { Wafer-Based }\end{array}$} & \multirow{2}{*}{$\begin{array}{l}\text { Eficiencia optimizada en Lab. } 26.7 \% \\
\text { Módulos rígidos. De 2-3 años para recuperar la } \\
\text { energía consumida en su fabricación }\end{array}$} \\
\hline & Si Poli-cristalino & & & & & \\
\hline \multirow{5}{*}{$\begin{array}{c}\text { II } \\
\text { Thin Film }\end{array}$} & GaAs & & $28.8 \%$ & & \multirow{5}{*}{$\begin{array}{l}\text { Película fina } \\
\text { inorgánica }\end{array}$} & \multirow{5}{*}{$\begin{array}{l}\text { Módulos rígidos } \\
\text { (disminuye la eficiencia) }\end{array}$} \\
\hline & Silicio TFS & & $08.0 \%$ & & & \\
\hline & CIGS & Menores & $22.6 \%$ & - & & \\
\hline & $\mathrm{CdTe}$ & & $22.1 \%$ & & & \\
\hline & Perovskita $(\mathrm{Pb})$ & & $22.7 \%$ & & & \\
\hline \multirow{16}{*}{$\begin{array}{c}\text { III } \\
\text { NTE }\end{array}$} & MJ 2 uniones ( $2 \mathrm{j})$ & - & $39.2 / 44.4$ & - & & \\
\hline & MJ 3 uniones (3j) & - & $32.8 / 35.5$ & - & ${ }^{3}$ M.J. Multi-unión & $\begin{array}{l}\text { Tándem N.M. semiconductores de } \lambda \text { específico, } \\
\text { múltiples uniones p-n. } \\
\text { Densidad de Potencia hasta } 776 \mathrm{~W} / \mathrm{m}^{2}\end{array}$ \\
\hline & MJ 4 uniones o más & - & $40.7 / 47.7$ & - & & \\
\hline & Perovskita $(\mathrm{Pb})+\mathrm{Si}$ & Menores & $30.0 \%$ & 3 & & Inestabilidad del Material \\
\hline & Perovskita $(\mathrm{Bi})+\mathrm{Si}$ & Menores & - & - & $\begin{array}{l}\text { Materiales } \\
\text { Híbridos }\end{array}$ & Libre de plomo y muy estables \\
\hline & Perovskita BaZrTiS $_{3}$ & - & $38,7 \%$ & - & & $\begin{array}{l}\text { Alto coef. de absorción } \\
\alpha, \text { compuesto no tóxico (Nishigaki, 2020) }\end{array}$ \\
\hline & Tintes sensibilizado & Menores & $11.9 \%$ & $>4$ & DSSC & Células en configuración Tándem \\
\hline & Orgánicos & Menores & $11.5 \%$ & - & \multirow{2}{*}{$\begin{array}{l}\text { Película fina } \\
\text { Orgánica }\end{array}$} & Flexibles / Transparente / Bio \\
\hline & ${ }^{2} \mathrm{BPV}$ & Menores & Baja & - & & Densidad de Potencia: $0.5 \mathrm{~W} / \mathrm{m}^{2}$ \\
\hline & Carbón Nanotubos & - & Alta & - & $\mathrm{CNT}$ & Antenas de CNT para captar luz \\
\hline & $\mathrm{Si}+$ Dieléctrico & Menores & Alta & - & PERC & Capa dieléctrica para reflectar fotones \\
\hline & $\mathrm{Si}+$ Concent. Ópt. & Menores & $44.1 \%$ & - & Lentes ópticos & Requiere menos material PV \\
\hline & QDSC - Quantum Dot & - & $12.6 \%$ & - & $\begin{array}{l}\text { Banda } \\
\text { Sintonizable }\end{array}$ & Mejoras de estabilidad (Choi et al., 2020) \\
\hline & LFSR Inorgánico & - & & \multirow{3}{*}{ H.C } & \multirow{3}{*}{ FV Reconfigurable } & Tándem LFSR configurable \\
\hline & LFSR Orgánico & - & Adapt. & & & Bi-facial / Bio-degradación selectiva \\
\hline & LFSR + Concent. Ópt. & - & Alta & & & Concatenación de ganancia LFSR \\
\hline
\end{tabular}

${ }^{1}$ NTE: Nuevas Tecnologías Emergentes, N.M: Nuevos Materiales, PERC: Passivated Emitter and Rear Contact, H.C: Hardware Circular

${ }^{2}$ Las celdas Bio-Fotovoltaicas BPV presentan baja eficiencia, pero aportan procesamiento de $\mathrm{CO}_{2}$

${ }^{3}$ Los reportes de eficiencia de las células Tándem M.J: Multi-Unión sin concentrador / con concentrador (NREL, 2020) 
para la investigación y configuración de materiales con tecnología DSSC y compuestos híbridos que permitan aumentar la eficiencia de conversión aplicando minería de datos, simulación y técnicas de aprendizaje sobre el módulo de I+D+i, concentración óptica, circuitos regenerativos, PERC, entre otras. Entre la matriz de composición, es necesario priorizar aquellos materiales compatibles con las tecnologías verdes, células solares orgánicas, pigmentos vegetales de clorofila (sintética), entre otros, planteando además la alternativa de tratamiento de la superficie del panel solar para la regeneración del compuesto con el fin de mejorar las condiciones de estabilidad de metamateriales diseñados para funciones específicas y propiedades regenerativas. En tal sentido, se ha incluido entre las nuevas tecnologías emergentes un modelo LFSR para la configuración dinámica de las celdas fotovoltaicas basado en la fabricación aditiva con la superposición de capas en arquitectura tándem. Este modelo concatena concentradores basados en la similitud entre el comportamiento de Stokes Shift con LFSR, realimentación reflexión interna (RIT) en concentradores ópticos (Sandoval, 2020a), filtros inteligentes y sistemas regenerativos RCR.

Este estudio ha permitido identificar capas funcionales de la celda fotovoltaica con coeficiente de eficiencia selectivo en un arreglo concatenado de aportes de conversión. Entre las capas en arreglo tándem, se presenta un retardo $\tau$ asociado al desplazamiento de los fotones/electrones (donde se requiere evitar la recombinación de estos últimos posterior a la conversión); además, se presenta la realimentación de fotones no convertidos para su aprovechamiento eficiente. A esta estructura se le incluyen las etapas previas de concentradores de radiación con estructura autosimilar en tanto que el almacenamiento corresponde a una etapa posterior a la conversión. Éste se lleva a cabo en tecnologías de ultra-condensadores, células electroquímicas fotosintéticas, entre otras, lo que permitió establecer la relación fractal del sistema. Un concepto tecnológico para energía fotovoltaica evolutiva está basado en un esquema LFSR-Reconfigurable con capacidad adaptativa de las capas del arreglo fotovoltaico para la formulación dinámica y adaptación de pesos de aprendizaje del modelo ANN, inspirado en estructuras de múltiples capas realimentadas. Se estudió la adaptación y optimización de los componentes y se generalizó el modelo, definiendo los componentes por correspondencia para optimizaciones escalables en diseños sobre hardware. La identificación permitió obtener un modelo de síntesis para los paneles solares híbridos. La correspondencia entre el modelo LFSR y los componentes propuestos de los arreglos fotovoltaicos es presentada en la tabla 2.

El modelo LFSR puede ser aplicado en fabricación aditiva con re-pigmentación, solucionando así el problema de estabilidad y logrando un avance significativo respecto al rendimiento. Asimismo, la consideración de materiales no sólidos enmarcados en láminas de vidrio que pueden ser reconfigurados por campo con el fin de obtener celdas PV regenerativas como una solución al impacto ambiental de la tecnología fotovoltaica actual. Se encuentra en esta estructura de capas concatenadas la alternativa de integrar una capa de registros de energía que serán las etapas intermedias para la realimentación. Finalmente, todas las capas funcionales pueden tener la opción de configuración por efecto de campo eléctrico en la matriz de energía solar PV, siendo estas características un aporte para la reutilización de elementos y materiales, dando flexibilidad al SFV. Un aspecto de interés corresponde al diseño inspirado en la capacidad de eficiencia de modelos naturales, en los que se analizan la estructura de la superficie de la célula fotovoltaica para obtener una máxima captación de 
energía solar, conversión de radiación de las diversas longitudes de onda recibidas, ajuste dinámico de las estructuras para mejorar la irradiancia sobre la superficie del panel, entre otras. Al plantear el desarrollo de sistemas FV eficientes, se deben considerar alternativas bio-inspiradas, pues ya en la naturaleza se presentan mecanismos óptimos de aprovechamiento de energía solar por su capacidad adaptativa, geometría fractal, almacenamiento, posicionamiento, colaboración y síntesis inteligente. Estos procesos pueden resultar en una alternativa de modelado de SFV, considerando los referentes a activación/reactivación selectiva, gestión de reservas de almacenamiento y seguimiento solar como se presenta en la Tabla 3.

Tabla 2. Correspondencia entre niveles tecnología fotovoltaica

\begin{tabular}{|c|c|c|c|c|}
\hline Nivel LFSR & Capa de Operadores & Almacenamiento & Realimentación & Selectividad \\
\hline Capa Cuántica & Material fotoeléctrico & $\begin{array}{l}\text { Tecn. de } \\
\text { Almacenamiento }\end{array}$ & $\begin{array}{l}\text { Re-Conversión de } \\
\text { energía }\end{array}$ & Diurno/nocturno \\
\hline Molecular & $\begin{array}{l}\text { operadores } \\
\text { moleculares }\end{array}$ & INHIBIT molecular & - & Electrónica molecular \\
\hline $\begin{array}{l}\text { Inter-capas } \\
\text { (Bandas) }\end{array}$ & $\begin{array}{l}\text { Activadores / } \\
\text { Convertidores }\end{array}$ & $\begin{array}{l}\text { Reacción de fotones } \\
\text { latentes }\end{array}$ & $\begin{array}{l}\text { Capa dieléctrica } \\
\text { (reflectante) }\end{array}$ & Long. de Onda. ( $\lambda$ adapt $)$ \\
\hline $\begin{array}{l}\text { Mecanismo For- } \\
\text { mulador }\end{array}$ & $\begin{array}{l}\text { Optimizador / } \\
\text { Concentrador portátil }\end{array}$ & - & $\begin{array}{l}\text { Dieléctrico portátil en par- } \\
\text { te trasera del panel }\end{array}$ & Filtros intercambiables \\
\hline $\begin{array}{l}\text { Semiconductores } \\
\text { in situ }\end{array}$ & $\begin{array}{l}\text { Concentradores Solar } \\
\text { Portátil }\end{array}$ & $\begin{array}{l}\text { Arena, cuarzo y mate- } \\
\text { riales para } \\
\text { micro-cristales }\end{array}$ & $\begin{array}{l}\text { Energía Solar, disminu- } \\
\text { ción de emisión de } \mathrm{CO}_{2} \\
1 / 9 \text { Ton }\end{array}$ & $\begin{array}{l}\text { Reactivo, análisis de } \\
\text { sub-productos }\end{array}$ \\
\hline $\begin{array}{l}\text { Revestimiento } \\
\text { funcional (fijo) }\end{array}$ & $\begin{array}{l}\text { Películas finas de reves- } \\
\text { timiento fotoeléctrico }\end{array}$ & - & $\begin{array}{l}\text { Películas finas de revesti- } \\
\text { miento dieléctrico }\end{array}$ & $\begin{array}{l}\text { Películas finas de } \\
\text { sensibilizador }\end{array}$ \\
\hline $\begin{array}{l}\text { Meta- } \\
\text { materiales }\end{array}$ & Moléculas fotoeléctrica & $\begin{array}{l}\text { Reacción de fotones } \\
\text { latentes }\end{array}$ & PERC (capa posterior) & $\begin{array}{l}\text { Pigmentos de sensibiliza- } \\
\text { ción ( } \lambda \text { adapt })\end{array}$ \\
\hline PV-FPCA & $\begin{array}{l}\text { Conversión PV configu- } \\
\text { rable por campo }\end{array}$ & $\begin{array}{l}\text { Reacción reconfigura- } \\
\text { ble de fotones latentes }\end{array}$ & $\begin{array}{l}\text { Configuración dieléctrico } \\
\text { de reflexión de fotones }\end{array}$ & $\begin{array}{l}\text { Configuración de } \\
\text { pigmento sensibilizador }\end{array}$ \\
\hline
\end{tabular}

Al estudiar las alternativas de almacenamiento de energía a partir de luz solar, se encuentra la posibilidad de síntesis por foto-activación, celdas o capas funcionales de registro de energía. En esta materia, se ha desarrollado el estudio en tecnología fotoelectroquímica que permite la conversión directa de energía solar a energía de almacenamiento químico como enlaces de Hidrogeno STH (Solar 
To Hydrogen). Las investigaciones giran en torno a la selección de propiedades del semiconductor a través de métodos de síntesis (Ver tabla 4).

Seguidamente, se define un arreglo de capas funcionales, identificado en etapas de optimización dentro de la composición estructural basados en foto-catalizadores (etapa frontal), modelo ANN de módulos de concentración HCPV (Almonacid, Fernández, Rodrigo, Pérez-Higueras, \& Rus-Casas, 2013), registro de almacenamiento de energía (Camargo-Silva, Muñoz-Prieto, Vera-Graziano \& Gomez-Pachón, 2017) y realimentación selectiva (etapa posterior), así como en las etapas intermedias y el mecanismo de gestión inteligente en el marco de la tecnología bio-fotovoltaica. El modelo LFSR para arreglos solares reconfigurable se basa en la integración de tecnologías fotoelectroquímica, biología molecular, física, mecánica cuántica, ciencias de materiales (ANN), cómputo avanzado y electrónica de hardware reconfigurable.

Tabla 3. Identificación de Bio-Funciones en Diseños de Sistemas Fotovoltaicos

$\begin{array}{lll} & \text { Bio- } & \text { Identificadores }\end{array} \quad$ Correspondencia en Aplicaciones Fotovoltaicas

\begin{tabular}{|c|c|}
\hline Fotosíntesis & Clorofila \\
\hline
\end{tabular}

Sensibilización por pigmentos en los paneles, a través de concatenación de operadores ponderados, sobre el espectro de radiación recibida.

$\begin{array}{lll}\begin{array}{l}\text { Activación de } \\ \text { semillas }\end{array} & \mathrm{H}_{2} \mathrm{O}+\text { Enzimas } & \begin{array}{l}\text { Foto-catalizadore } \\ \mathrm{TiO}_{2}\end{array} \\ & & \\ \begin{array}{l}\text { Reservas } \\ \text { inteligentes }\end{array} & \text { Energía }-\mathrm{H}_{2} \mathrm{O} & \mathrm{CSL} \\ & & \\ & & \\ \text { Germinación } & \begin{array}{l}\mathrm{H}_{2} \mathrm{O}+\text { Energía } \\ (\text { Temperatura })\end{array} & \mathrm{H}_{2} 0 \rightarrow \mathrm{H}_{2}+1 / 2 \mathrm{O}_{2}\end{array}$

Activación de foto-catalizadores para simplificar la descomposición de las moléculas, en materiales (no sólidos, con espacios vacíos en su estructura $>$ energía transformada). Control por efecto campo eléctrico.

Inhibidores de reacción para almacenamiento de fotones en estado latente y Regeneración de enlaces de manera controlada

Celdas Foto-electroquímicas disociación de agua para producir Hidrogeno Reconfiguración inteligente de estructuras del convertidor fotovoltaico.

Aprendizaje ANN por refuerzo, con bio-tutoría de plantas naturales, a través de sensores de fibra óptica anclados a árboles o enredaderas para aprender su comportamiento. Esquemas de control y electrónica de potencia MPPT. 
Tabla 4. Características de Tecnología Foto-electroquímica

$\begin{array}{ccc}\text { Materiales fotovoltaicos } & \text { Eficiencia } & \text { Características } \\ \eta & & \end{array}$

$\mathrm{AgBiS}_{2}$ (Bernechea, Miller, Xercavins, So, Stavrinadis, Konstan, 2016)

$\mathrm{Bi}_{2} \mathrm{WO}_{6}$ (Madriz, Tatá, Cuartas, Cuéllar \& Vargas, 2014), (Cereceda, 2018)

(Díaz-García, 2017)

(Li et al., 2015; Young et al., 2017)

Bio-electoquímica (Cevik et al., 2020;

Pankratov, Pankratova \& Gorton, 2020)
Proceso en solución a temp $<100^{\circ} \mathrm{C}$. Espesor capa activa de solo $\sim 35 \mathrm{~nm}$

Método hidro-térmico (asistido por microonda), caracteriAlta zadas por microscopía electrónica de barrido, Espectroscopía ${ }^{1} \mathrm{UV}$-Vis. $\mathrm{Bi}_{2} \mathrm{WO}_{6}$ absorción espectro luz visible

Las técnicas de síntesis por sol-gel y electro-depósito son eficaces y no requieren equipamiento sofisticado.

Dispositivos monolíticos integrados en tándem basados en elementos de los grupos III-V

Densidad de potencia de $42.2 \mathrm{~W} / \mathrm{m}^{2}$ al optimizar el mecanismo fotosintético de las algas verdes, usando concentración de Boro, aplicadas en celdas de combustible

Donde se aplican técnicas de caracterización, tales como electroscopía de dispersión EDX, difracción de rayos X ERX, espectroscopia en la región visible (espectrofotómetro), para el análisis de composición.

${ }^{1}$ Espectroscopía Ultravioleta visible UV-Vis de reflectancia difusa.

\subsection{Fractal Programmable Converter Array - FPCA}

Una matriz programable de ordenamiento está basada en una batería de elementos para composición de materiales fotoeléctricos, la cual es responsable de la configuración de las propiedades del material y es definida por un software para la síntesis de material optimizado. De esta manera, pueden interactuar con diseños ya implementados y optimizar sus funciones desde la actualización de infraestructura convencional sostenible hasta centrales eléctricas con nuevas tecnologías más eficientes y respetuosas con el medio ambiente. Esta propuesta permitiría realizar estimaciones de eficiencia, estrategias de optimización y mantenimiento preventivo de los paneles fotovoltaicos (mecanismo robótico, ventilación forzada y circuitos recuperadores de calor) para lograr ampliar la vida útil de los equipos. Por otra parte, se deben programar medidas de gestión de residuos de los paneles PV, dado el volumen que representan las instalaciones solares en la actualidad. Esto se da reutilizando componentes del SFV, lo que requiere menor consumo de energía que los procesos de reciclaje de materiales que sean inocuos con el medio ambiente. Partiendo de la afirmación "si 
se distribuyen responsabilidades del reciclaje a los fabricantes, esto les ayudará a tener en cuenta el ciclo de vida de un producto durante la fase de diseño", se deberán diseñar paneles solares con alternativas de reciclaje programados. Acá se propone un marco estructural configurable con acopladores geométricos y composición con ponderación selectiva. El diseño conceptual del mecanismo propuesto se presenta en la Figura 1.

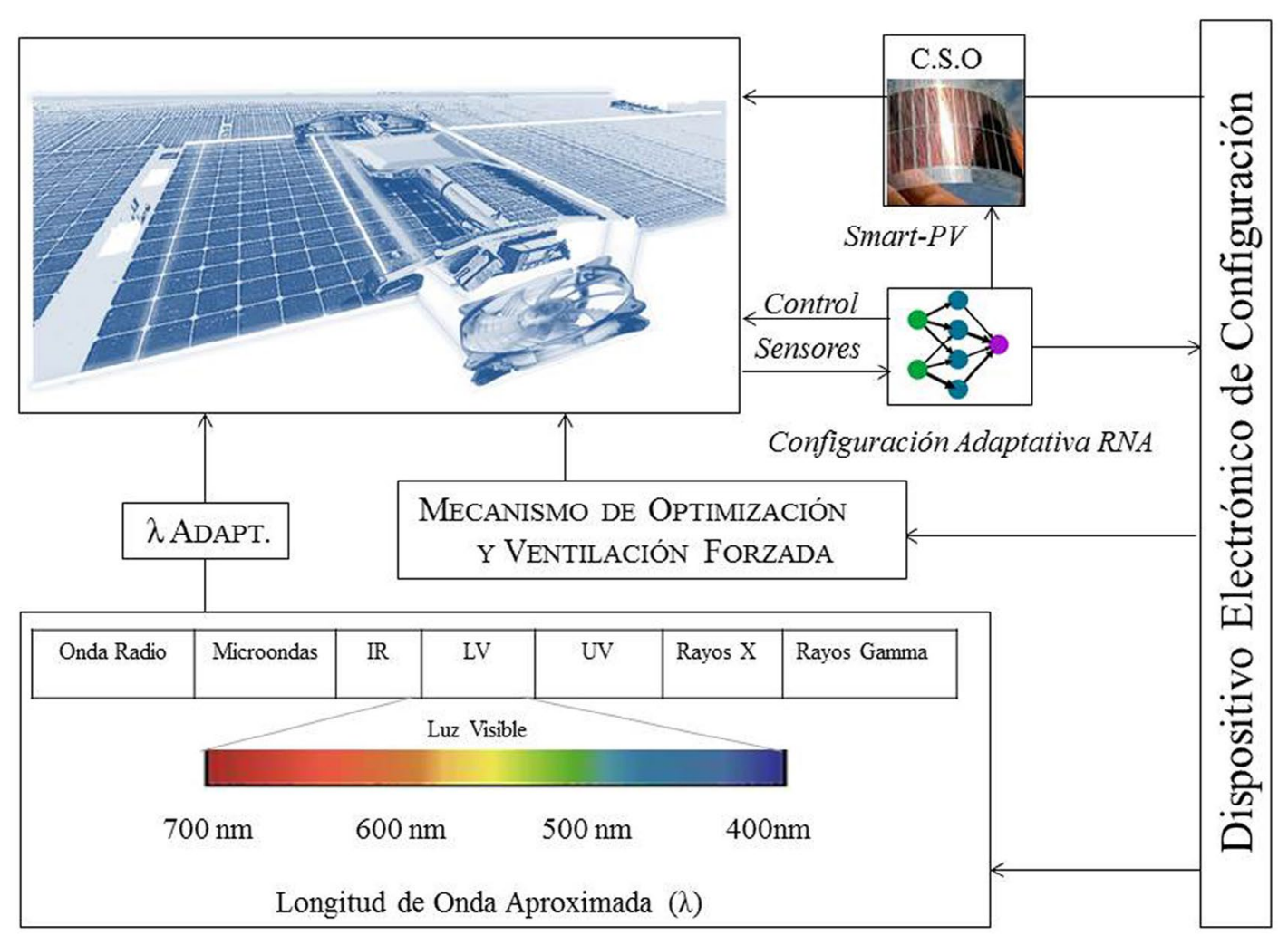

Figura 1. Diseño Conceptual del Mecanismo de Optimización

Acá se plantea la aplicación de Artificial Neural Network (ANN), digitalización de señales y gemelos digitales para el diseño o actualización de las células fotovoltaicas ya instaladas. También se plantea la combinación de hardware reconfigurable para implementar compuestos de pigmentación con el fin de obtener un mejor rendimiento en los paneles solares, entre ellos la pigmentación verde en las celdas solares en correspondencia con los sistemas fotosintéticos, y la consideración de más de un canal para capturar energía solar y hacer la conversión eficiente en la liberación de electrones. La plataforma está pensada con el objetivo de lograr un sistema inteligente basado en ecuaciones generalizadas de objetivos que permita la configuración particular, adaptación de los parámetros y ponderaciones, así como la optimización del arreglo. Uno de los importantes aportes corresponde al diseño programado por capas para el reciclaje y gestión de materiales componentes.

\subsubsection{Reconfiguración Dinámica del Arreglo Fotovoltaico.}

El modelo teórico permite el desarrollo de tecnología solar híbrida y microredes de energía basados en circuitos LFCS (Sandoval, 2018b). El concepto de LFSR_PV es novedoso, ya que ofrece 
una generalización del arreglo e introduce elementos de memoria y realimentación selectivas. Las estructuras nanoelectrónicas de material fotovoltaico pueden ser reordenadas con el fin de establecer un modelo matemático de estructuras con propiedades ópticas, fotoeléctricas y termoeléctricas controlables en el material semiconductor con composición tándem. Allí, la optimización de la estructura logra una mejora exponencial en la eficiencia del panel en relación con la irradiancia, potencia incidente por unidad de superficie de todo tipo de radiación electromagnética, en este caso radiación recibida solar (directa y difusa) expresada en $\mathrm{W} / \mathrm{m}^{2}$.

\subsubsection{Actualización Tecnológica.}

Entre las nuevas tecnologías se plantea el análisis de imágenes con inteligencia artificial, drones de monitoreo y robótica (Valero-Moro, Bonilla-Turmero \& Sandoval-Ruiz, 2017). Para la actualización de paneles solares instalados, se emplean sistemas robóticos en: ensamblaje de paneles solares, limpieza para mínimo consumo de agua (rodillos repasadores, vapor de agua, barrido superficial con aire comprimido, etc.), inspección (condiciones del sistema de generación y matriz de conmutación a través de reconocimiento de imágenes, termografía y rendimiento) y mantenimiento (sistema de seguimiento, configuración del punto de máxima irradiancia y respuesta de los actuadores, pruebas eléctricas y acoplado de etapas del sistema). En esta propuesta se plantea en robótica de adaptación dinámica de las instalaciones como: concentradores, estabilización térmica para implementación de concentración, sensibilización por pigmentos orgánicos para aprovechamiento de la radiación en diversas longitudes de onda, regeneración de componentes, almacenamiento y revestimiento inteligente de materiales biodegradables que permita simplificar la reutilización de componentes de los sistemas de energía solar. Esta alternativa de la actualización de los paneles instalados a través de mecanismos inteligentes comprende la reconfiguración de lentes del sistema óptico de concentración y capas del arreglo tándem a través de un dispositivo móvil que realice el barrido de forma modular del panel FV, optimizando la eficiencia.

\subsubsection{Componentes de Paneles Solares Fotovoltaicos Regenerativos}

En la línea de paneles fotovoltaicos reconfigurables se propone el diseño de cubiertas frontales (superficie de material regenerativo, cambio por eliminación o des-habilitación remota para tratamiento de la superficie del panel sin consumo de agua), es decir, un revestimiento configurable a través de un control selectivo con filtros programables; todo esto con el objetivo de mejorar la eficiencia. Por otra parte, la aplicación de ANN e inteligencia artificial permite soportar la clasificación de materiales funcionales como medida de solución a la obsolescencia programada. Esto se logra integrando conceptos de reciclaje electrónico, materiales fotoeléctricos y sustratos reutilizables en el concepto de hardware circular. Se debe tener en cuenta las investigaciones recientes donde se han presentado células solares de tres o cuatro capas diferentes de material, optimizadas para hacer uso de las diferentes longitudes de onda de luz que componen el espectro solar con técnica de despegue epitaxial en donde el material se despega del sustrato y éste puede ser reutilizado (ESA, 2020). Esto representa un aporte importante respecto al impacto ambiental de las tecnologías fotovoltaicas por la posibilidad de reciclaje de las células solares. 


\subsubsection{Re-pigmentación DSSC en arreglo fotovoltaico}

Uno de los retos que se presentan en los pigmentos orgánicos corresponde a la degradación por luz y la inestabilidad, lo que hace que estos panales requieran ser regenerados de manera periódica. El modelo LFSR, con realimentación lineal, se plantea como una solución para re-pigmentar las celdas fotovoltaicas y así garantizar el rendimiento óptimo del arreglo en el tiempo. La actualización sobre un sistema instalado de paneles fotovoltaicos de silicio se puede plantear como un mecanismo móvil que incorpore los dispositivos de optimización (filtros, concentradores, recuperadores de calor) sobre las células solares en un barrido secuencial. Entre los componentes se adiciona un sistema de ventilación para el control de temperatura del panel fotovoltaico, partiendo de reportes de eficiencia fotovoltaica mejorada en un $23.9 \%$ que aplican materiales de cambio de fase (PCM) en comparación con la fotovoltaica convencional (Hassan et al., 2020). Se plantea un carro móvil con un lente de polarización para un efecto remanente sobre las células de material semiconductor de silicio y un revestimiento correspondiente a la impresión sobre el panel de C.S.O (Células Solares Orgánicas), siendo estas transparentes en configuración tándem con el panel de instalado. En las investigaciones se establecen un conjunto de factores que inciden sobre la eficiencia del panel fotovoltaico. Estos pueden ser considerados para la optimización de forma dedicada o bien de forma compartida. Una de las propuestas es compartir recursos electrónicos como lentes de concentración, filtros de longitud de onda selectivos, sensibilizadores a base de pigmentos y reciclaje de calor a través de circuitos de recirculación de calor y materiales termoeléctricos. En la implementación se puede definir el método de diferencias finitas para estimación de recursos hardware (Sandoval, 2019b), basado en las ecuaciones del modelo para extrapolación del comportamiento y características de implementación.

\subsubsection{Multiplexado Espacio-Temporal de Tándem FV}

Se analizan las características de construcción de los materiales fotovoltaicos que componen la tecnología de células solares, considerando la energía consumida en el proceso de fabricación, su efecto contaminante del material y su costo. Una solución ya estudiada es reducir el área del material fotovoltaico a través de un arreglo óptico de concentración solar para aumentar la eficiencia de la célula fotovoltaica con menor material. En este punto se plantea la multiplexación del material que se requiera optimizar, creando un mecanismo robótico de desplazamiento sobre el eje $x$ y eje $y$ del panel solar. Se incluyen en este un porta-filtro para implementar filtros ópticos, material fotovoltaico en configuración tándem y técnicas de optimización en espacio y tiempo, considerando una resolución de conversión discreta y aplicando flash de luz (concentrada / polarizada) para alcanzar un efecto híbrido del sistema fotovoltaico en tema de eficiencia. Se plantea un conjunto porta-capas para el arreglo móvil de lentes polarizadas con el fin de aprovechar la luz en la longitud de onda específica para el arreglo fotovoltaico. Asimismo, un arreglo tándem de material fotovoltaico, el efecto del arreglo tándem (multiplexado) en las células del panel, permitirían mejorar su eficiencia. Algunos de los arreglos presentan inestabilidad, efecto de polarización y otros factores que reducen el rendimiento con la atención regular en el procedimiento de mantenimiento regenerativo del panel solar. Se plantea la reconfiguración dinámica de los componentes y así la estabilización óptima 
del mismo. En el estudio de la fotosíntesis artificial, se plantea tanto la síntesis del material PV en sitio a través de un arreglo reconfigurable, así como la incorporación de tintes vegetales (clorofila sintética) o paneles fotosintéticos basados en algas y composición vegetal para ampliar el alcance de la instalación en términos de conversión de energía y almacenamiento de energía en las celdas de conversión.

\subsubsection{Redes Neuronales para SFV Inteligentes}

En el diseño de compuestos de materiales fotovoltaicos se puede aplicar una matriz de evaluación de eficiencia, estabilidad, nivel de toxicidad, reutilizabilidad, impacto ambiental y otros factores determinantes en el comportamiento de los paneles solares. De esta manera, se diseña un LFSRFormulador Inteligente basado en estructura de realimentación lineal, aplicando ANN para la adaptación de pesos de cada capa.

\subsection{Método de Configuración del Esquema LFSR de la Red Neuronal Artificial}

Se seleccionó una red neuronal Perceptrón Multicapa (MPL) por sus características de generalización y estructura circuital, que permite su adaptación al esquema LFSR en configuración Galois. El esquema de ANN ha sido tratado como operadores de composición de una red fractal (Sandoval, 2020b) bajo el criterio de establecer operadores neuronales con un modelo VHDL simplificado, entrenamiento fraccionado de subredes y sus conexiones de interacción a través de un sistema de funciones iteradas. Esto permitiría optimizar el arreglo neuronal. Para el caso de los neuro-operadores con entrenamiento supervisado (Sandoval, 2020b) en la definición de los coeficientes del arreglo LFSR, se aplica como método de optimización de la función de costo el algoritmo de descenso por gradiente (Gradient Descent). Para esta aplicación, el entrenamiento reportó un error de 7.24E-7, luego de 2000 épocas de entrenamiento con una constante de aprendizaje de 0.001. La red neuronal fractal permite concatenar esquemas de control inteligente en la optimización del sistema fotovoltaico a nivel de composición tándem de celdas fotoelectroquímica, seguimiento solar, refrigeración de celdas, concentración, etc., con relación a aprendizaje por refuerzo para las variables ambientales de irradiancia y aprendizaje supervisado en subredes de target conocido, superando los mínimos locales del MPPT.

Se modeló un arreglo fotovoltaico con topología LFSR. Los IPVD programables y el selector de realimentación serán los responsables de la configuración de la matriz programable de paneles solares. Un panel fotovoltaico híbrido o arreglo de células PV se comporta como una red neuronal PV, por lo que se realizó el modelado del sistema de potencia partiendo de (2):

$y_{s}=\sum_{j=1}^{n-k} w_{j}\left(\sum_{i=1}^{m} w_{i} \cdot x_{i}\right)+b$

Al sustituir el aporte de cada una de las etapas (coeficientes de las capas del sistema fotovoltaico) y la realimentación de los registros de energía y calor $y_{s-1}$, se tiene el modelo dado por (3): 


$$
y_{s}=w_{c S} *\left[\left(w_{s i}+w_{c s o}+w_{p s k}\right) \cdot x_{i}\right]+y_{s-1}
$$

Donde la eficiencia está dada por los pesos del optimizador: seguidor/concentrador (para el caso práctico se simuló el sistema de seguimiento solar en dos ejes) y convertidor en arreglo tándem (LFSR). Cada uno de estos coeficientes será definido y adaptados de forma dinámica por la ANN diseñada en VHDL.

\section{RESULTADOS}

Tabla 5. Propuestas de Tecnologías de Optimización

Propuesta Descripción

Cristalización de Silicio in situ

\section{PV-FPCA}

Paneles Solares Inteligentes

Mecanismo

Robótico

Multi-Funcional

Estados de materiales
La producción local de paneles fotovoltaicos con un concentrador móvil (mecanismo robótico) que, empleando energía solar de concentración térmica, alcance la temperatura de tratamiento de la arena para la purificación del Silicio Solar (aprox. $900^{\circ} \mathrm{C}$ ), disminuya las emisiones de $\mathrm{CO}_{2}$ de fabricación, ensamblaje y transporte, y simplifique la fabricación y permite la obtención de microcristales para reparaciones y ampliación de la vida útil del módulo.

Capas concatenadas de semiconductores y sensibilización de pigmentos orgánicos, análisis de bajo impacto ambiental durante fabricación, operación y desmontaje. La capacidad de programación por campo o reconfiguración por síntesis selectiva de compuestos, lo hace un panel fotovoltaico de hardware circular, con formulación, adaptación y reconfiguración dinámica, que permite máxima eficiencia y simplificación del proceso de mantenimiento y actualización tecnológica.

La inteligencia artificial está planteada para tareas de formulación y diseño de materiales, robótica de mantenimiento regenerativo y reciclaje inteligente. Más importante aún, la inteligencia natural incorporada y emulada a partir de materiales orgánicos, procesos fotosintéticos de seguimiento de luz y almacenamiento de fotones, síntesis y procesamiento de $\mathrm{CO}_{2}$, combinando paneles de bioremediación (vegetación en sistemas hidropónicos y algas).

Programable para funciones de la superficie frontal y posterior del panel fotovoltaico. Limpieza, concentración, sensibilización, tándem multi-unión, capa de realimentación (por dieléctrico), circuitos de recuperación de calor regenerativo, ventilación forzada, entre otros.

Densimetría del material y su comportamiento como donador y receptor en la conversión fotovoltaica. Reacción de fotones para estar en estado de latencia, activación controlada (por campo), para reactivación programada, inspirada en inteligencia natural de los materiales. 
Los resultados vienen dados por las ecuaciones del modelo matemático del arreglo fotovoltaico híbrido en función de la caracterización multicapa, descripción VHDL de los componentes de la estructura LFSR y el generador de red neuronal para optimización dinámica del arreglo solar. En esta investigación, se propone la superposición tándem a través de capas en configuración LFSR con realimentación entre ellas que permita ampliar la eficiencia, así como el almacenamiento de fotones y mayores índices de absorción para la conversión de energía. De esta manera, se proponen los siguientes conceptos (ver Tabla 5).

El concepto tecnológico seleccionado para la plataforma parte de una composición Fractal-LFSR, que puede ser ampliado a partir de aplicaciones precedentes en el campo de las energías renovables (Sandoval, 2019c). Se establece la formulación matemática para la ANN, que modela el sistema fotovoltaico reconfigurable, compuesto de un arreglo de aportes paralelos en configuración tándem y de un sistema óptico que comprende lentes, concentradores, capa anti-reflexión, geometría fractal, propiedades físicas de los materiales y configuración del arreglo óptico. Un sistema de seguimiento permite mejorar la eficiencia en el orden de $5 \%$ (Fernández- Ahumada et al., 2020), compuesto por sensores de monitoreo, motores de accionamiento, estructura y lógica de control para el manejo de estos. El mecanismo de optimización por multiplexado estará definido en dos ejes. La síntesis de materiales funcionales se puede definir a partir de componentes minerales o compuestos biológicos inspirados en los procesos de fotosíntesis de las plantas. Actualmente se adelantan proyectos de naturalización urbana de espacios, infraestructuras verdes, entre otros, siendo de interés el estudio de circuitos de fotocatalizadores (óxidos metálicos sintetizables, clorofila, algas, etc.) para integrar funciones de remediación ambiental.

Llegado a este punto, la base para la red de ordenamiento estará basada en ponderadores o dosificadores de los componentes en una formulación dinámica para obtener el comportamiento proyectado. Asimismo, se contará con una batería de componentes y una memoria de fórmulas obtenidas para su optimización, es decir, la combinación, selección y realimentación de los compuestos o materiales en el arreglo estructural. Estos componentes comprenden una arquitectura LFSR que será el operador de configuración para el diseño. La principal potencialidad es la definición de un modelo como concepto tecnológico basado en hardware reconfigurable, que permite describir el comportamiento de estructuras fractales LFSR (inspiradas en la naturaleza) como un código de generación para fotovoltaica. De esta manera, con el avance de la tecnología, se puede actualizar la implementación, respetando criterios de sostenibilidad y hardware circular, reciclando en el mecanismo diseñado componentes y materiales por dosificación / habilitación de estructuras del convertidor de energía. El modelo se ilustra en la Figura 2.

El esquema busca integrar aportes tecnológicos (ver Tabla 6) en una matriz de hardware reconfigurable a través de dispositivos electrónicos inteligentes para fotovoltaica, manejados por tecnología FPGA.

Se define un código que permitirá la configuración inteligente, la síntesis de materiales en relación con la función objetivo, la reparación de capas, polarización, aumento de eficiencia, reclasificación y actualización sin producir residuos. 


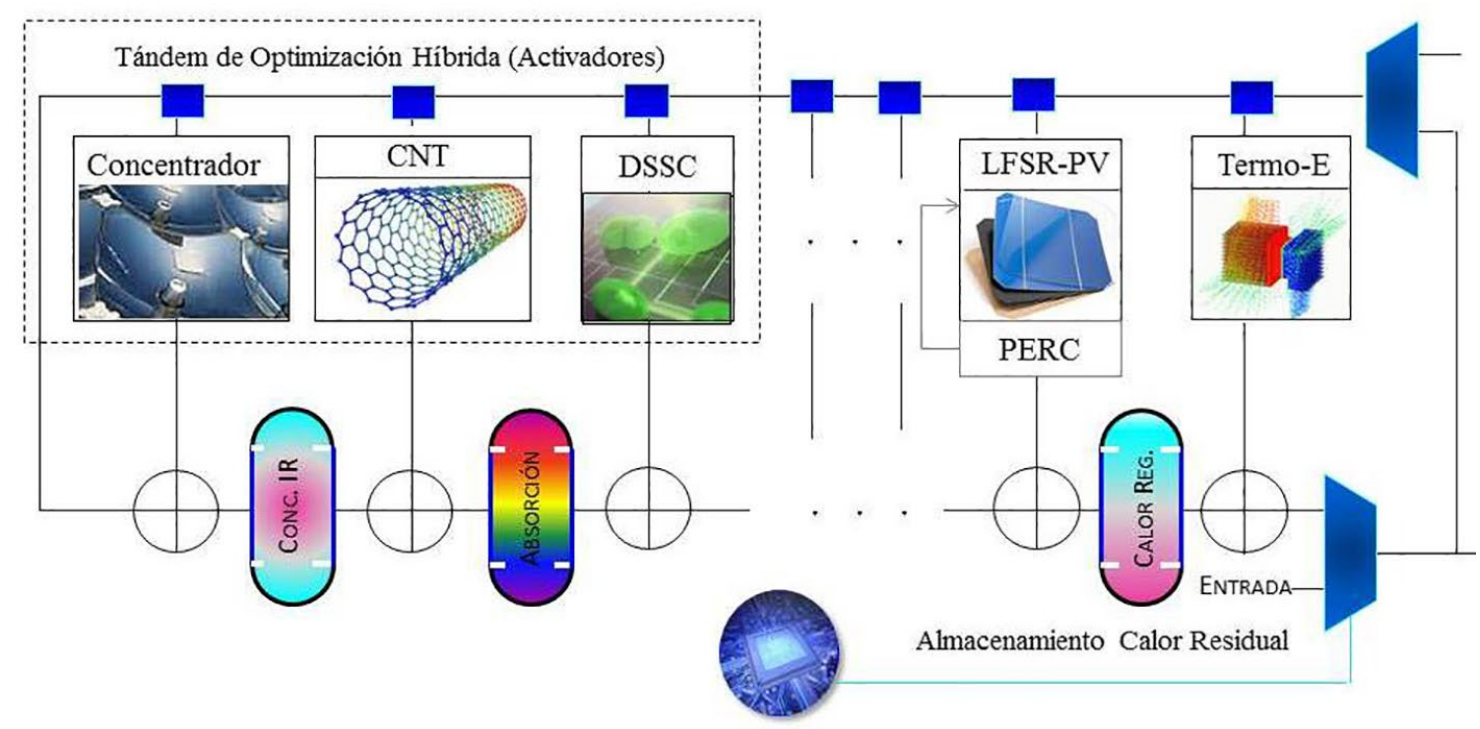

Figura 2. Esquema Fractal-LFSR en Sistemas Reconfigurables de Conversión de Energía

Tabla 6. Aportes de modelo PV-LFSR

\begin{tabular}{|c|c|c|c|c|}
\hline Aporte del Modelo & A nivel de arreglo & A nivel de Materiales & Modelo Teórico & Ambiental \\
\hline Simplificación & Diseño Modular & Enlaces simples & $\begin{array}{l}\text { Ecuación } \\
\text { generalizada }\end{array}$ & $\begin{array}{l}\text { Mínimo consumo } \\
\text { de energía }\end{array}$ \\
\hline Flexibilidad & Módulos Configurables & Control de propiedades & Formulación in situ & Hardware Circular \\
\hline Regeneración & Diseño Regenerativo & Re-activación & $\begin{array}{l}\text { Actualización } \\
\text { Dinámica }\end{array}$ & Biodegradables \\
\hline Eficiencia & Arreglo para $\lambda$ adapt. & Máxima conversión & $\begin{array}{l}\text { Concatenación de } \\
\boldsymbol{\eta}_{\text {parcial }}\end{array}$ & Minimiza Impacto \\
\hline
\end{tabular}

Los módulos solares serán como árboles que pueden escalar de manera fractal su composición hasta llegar al nivel de nanotecnología, manejo de polarización de las lentes y nivel cuántico para el ordenamiento de los componentes en la configuración dinámica de los materiales, basados en las condiciones climáticas, objetivo de eficiencia y propiedades de la estructura en el proceso de hardware circular. La implementación de un sistema de configuración dinámica necesita elementos discretos como sensores de irradiancia, algoritmo que determine continuamente la configuración óptima y la matriz de conmutación. Estas configuraciones son detalladas en González (2015) además de la 
estructuración de capas. En primer lugar, se definió un control del sistema, un operador básico, que tiene arquitectura similar a la propuesta para la tecnología solar reconfigurable. Se trata del operador $\operatorname{LFC}(n, k)$ en una matriz generalizada, que permitirá ponderar los aportes de componentes en el autoordenamiento inteligente de la estructura (Sandoval, 2020c), como se presenta en la Figura 3.

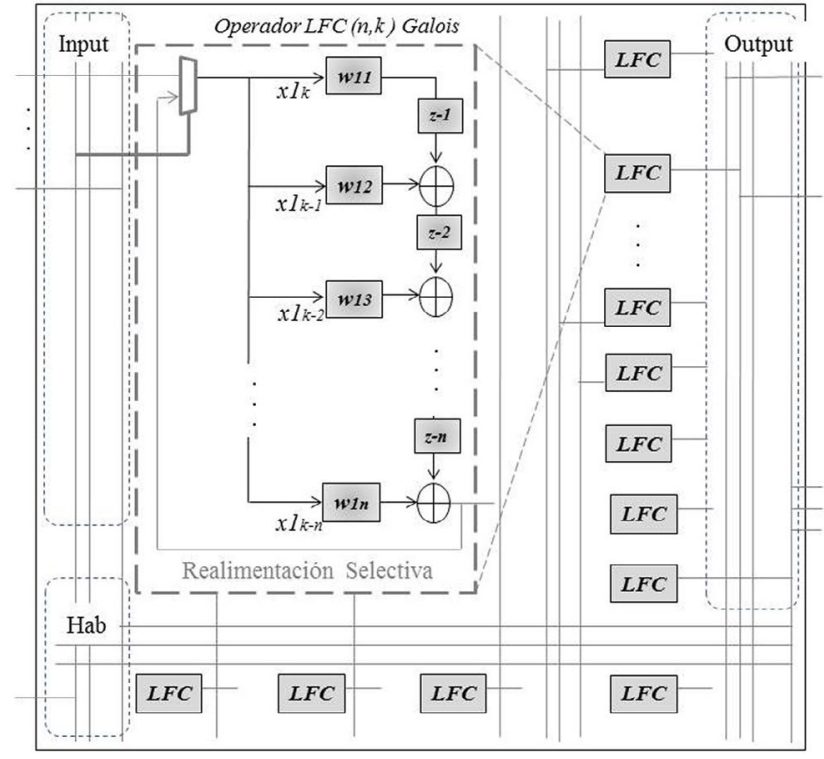

(a) Matriz de Control FPGA

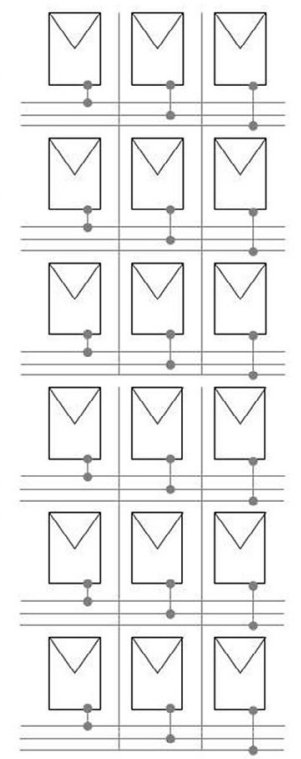

(b) Matriz de Conmutación

Figura 3. Matriz de Operadores LFC $(n, k)$ para Arreglo Configurable PV

Definida la arquitectura del operador básico, es posible definir un arreglo de geometría fractal para la aplicación de configuración de los paneles fotovoltaicos. Se plantea la investigación en materiales inteligentes que permitan la reconfiguración dinámica de los paneles solares además de la biodegradación selectiva del material. Esto será desde el sistema solar distribuido con interconexión a la red inteligente, parques solares de investigación y arreglos solares portátiles para la producción de energía como sistemas de respaldo. El problema de optimización de la tecnología solar (fotovoltaica o termoeléctrica) está sujeto al diseño de materiales con propiedades de alta eficiencia que puedan ser adaptados a las condiciones dinámicas. Los dispositivos de hardware reconfigurable pueden ser la alternativa para la implementación de modelos altamente eficientes de tecnología solar. Esto a partir de la identificación de correspondencia entre componentes de la estructura LFSR, basado en una técnica de reordenamiento y concatenación de operadores lógicos en un arreglo $\operatorname{LFC}(n, k)$ de estructuras secuenciales de configuración (Sandoval, 2012) para sistemas instalados que requieren multiplexado en el tiempo para atención de las celdas FV de modelos diseñados con hardware dedicado.

A partir de la relación entre capas del arreglo solar, se ha desarrollado una ecuación que describe la concatenación fractal de los operadores fotoeléctricos estandarizados en configuración dada por (4): 


$$
f_{t}(x)=\&_{i=0}^{n-k} f_{t-1}(i-1) \oplus\left[\left(G(i) \oplus f_{t-1}(n-k-1)\right) \otimes C(i)\right]
$$

Donde $\mathrm{F}(x)$ corresponde a la operación matemática $\operatorname{LFC}(n, k)$, resultante entre $\mathrm{G}(x)$, irradiancia recibida, y $\mathrm{C}(x)$, el polinomio característico del convertidor fotovoltaico. Este último corresponde a los coeficientes de conversión donde se concatenan las operaciones parciales correspondientes a las salidas de conversión por capa en la posición $i$, siendo $i-l$ la posición más profunda del arreglo en donde se realimenta la energía no convertida del espectro. En este caso, se ha representado el multiplexado en el tiempo del arreglo tándem con registros secuenciales de resultados de conversión parcial. Este enfoque permite identificar los parámetros a optimizar, donde las ANN pueden aportar en la adaptación de la matriz $\mathrm{C}(x)$ para la formulación dinámica de materiales fotoeléctricos inteligentes, siendo reformulado el operador descriptor del arreglo (5):

$$
f_{t}(x)=\&_{i=0}^{n-k} f_{t-1}(i-1) \oplus\left(\oplus_{t=1}^{m} g(i) \oplus f_{t-1}(n-k-1)_{t} \text { and } c(i)_{t}\right)
$$

De esta forma, los productos internos del arreglo fotoeléctrico (operadores de conversión) para cada coeficiente del polinomio generador del arreglo LFC (propiedades que definen el comportamiento de la estructura) coincide con los pesos característicos definidos del material híbrido. El modelo teórico desarrollado permite la descripción en VHDL de los operadores basados en circuitos LFCS, estableciendo una relación directa entre operadores matemáticos y operadores neuronales. Se logra definir un esquema circuital parametrizable para la estimación de recursos de hardware. De esta manera, las optimizaciones realizadas sobre un circuito base pueden ser extrapoladas en aplicaciones generales como fotovoltaica reconfigurable y síntesis dinámica de capas del convertidor FV.

\subsection{Aplicación del Modelo Fractal ANN}

El modelo fractal ANN simplifica la descripción VHDL de sistemas adaptativos con variables acotadas a través de un modelo de funciones iteradas en el sistema conexionista. El aporte a nivel de ingeniería está dado por las ecuaciones matemáticas para la generación de código hardware como soporte para la implementación de SFV regenerativos. Es decir, se define una función específica LFSR y se reconocen los patrones autosimilares en el modelo del concentrador, celdas fotovoltaicas y control para establecer la optimización. Esto además permite la reutilización de hardware y elementos circuitales de operadores básicos que son componentes del modelo. Cada subred, según el nivel de profundidad circuital, tiene sus parámetros particulares: dimensión de las señales, complejidad del operador (a mayor profundidad los operadores serán circuitos autosimilares internos y capacidad de almacenamiento), lo que lleva a una identificación de correspondencia entre las aplicaciones para las etapas del sistema de potencia y control. Todo esto con la misma arquitectura LFSR que define el patrón fractal. El arreglo puede ser adaptado en forma secuencial para redes externas y circuitos concurrentes para subredes internas de acuerdo con la aplicación. 
Tabla 7. Definición de Componentes LFSR

Definición del Componente en VHDL

Código VHDL del Comportamiento

Operador LFSR interno (representación neuronal)

entity Red_Neuronal is

port ( yp: in std_logic_vector (7 downto 0); ...

wij: alg port map (wd,xi,yi); -- wn+1 <= función_

de_aproximación(wn)

d1: TDL port map (in,out);

c1: capa_sigma port map (yp,u,a1);

n1: neurona port map (pi,wi,bi,y1);

-- Configuración de las capas intermedias y las neu-

ronas componentes

$\mathrm{nS}$ : neurona port map (pi,wi,bi,yS);

cS: capa_lineal port map (a1, ym); -- Capa de Sa-

lida
U1: Identificador_Sistema Port Map (x1,x2,x3, y1,y2);

U2: Controlador_Neuronal Port Map $(\mathrm{u} 1, \mathrm{~d} 1, \mathrm{y} 1)$;

...

-- Modelo Neuronal / Códigos Reed Solomon / LFC (n,k)

-- Concatenación ponderada con realimentación lineal LFCS

u1: a2<=a1(6 downto 4) \& (a1(3) xor a1(7)) \& (a1(2) xor $\mathrm{a} 1(7)) \&(\mathrm{a} 1(1)$ xor a1(7)) \& a1(0) \& a1(7);

-- Generación de términos del LFSR:

-- ut: at $+1<=$ at(i) xor $($ at $(m-1)$ and p(i) \& ... for $\mathrm{i}=\mathrm{m}-1$ to 0

Elemento de Almacenamiento/ Registros configurables

entity Almacenamiento is

port ( clk : in std_logic;

Ent : in std_logic_vector ( $m$ downto 0 );

Sal : in std_logic_vector (m downto 0 );

Eo : out std_logic; -- Habilitación controlada

(opcional)

end almacenamiento; architecture Behavioral of Almacenamiento is

process (clk)

begin

if clk= ' 1 ' and clk'event then

Sal <= Ent; end if;

end Behavioral;

Arreglo de Realimentación Selectivo (Multiplexor)

entity Selector is

port ( I : in std_logic; -- Entrada de Ctrl. selectora

Ent0, Ent 1 : in std_logic_vector ( 3 downto 0$)$;

Sal: out std_logic_vector (3 downto 0);

End Selector; architecture Behavioral of Selector is

process (I)

begin

if I = '0' then $\mathrm{Sal}<=$ Ent0; Else Sal <= Ent1; end if;

end Behavioral;

El concepto tecnológico corresponde a la combinación de manejadores FPGA y capas selectivas en la composición LFSR de una célula de conversión de energía solar. Dos puntos de innovación serían (1) una matriz de componentes finitos para combinaciones de arreglos, lo que se traduce en mayores alternativas de optimización y la ampliación de la eficiencia y vida útil del panel, y (2) la disminución de costos para sistemas distribuidos, en donde se pueden configurar los m elementos del arreglo de acuerdo con sus características y condiciones. El optimizador correspondería a una red de ordenamiento (en un dispositivo electrónico FPGA) y una red de reserva (una matriz de elementos componentes para la configuración del módulo fotovoltaico) con monitoreo de eficiencia, 
configuración dinámica y realimentación (calor residual a módulos con materiales termoeléctricos) para la producción de energía regenerativa. De esta manera, se tiene un sistema inteligente con un control electrónico por ANN implementado en dispositivos FPGA con convertidor de energía y mecanismo de accionamiento para posicionamiento, matriz de conmutación del arreglo FV y sistema distribuido con operación remota de los equipos del sistema eléctrico de potencia, en el marco de una plataforma tecnológica para el teletrabajo.

Todo esto permite alcanzar la reducción de consumo de energía en el proceso de producción, un modelo de hardware circular, un impacto ambiental mínimo y la optimización dinámica para lograr mayor eficiencia en las nuevas tecnologías. Si se diseñan soft-solar panel, es decir paneles solares definidos por software con elementos suaves en la composición de la cámara fotovoltaica / capas (composición inteligentes) que pueden ser reconfigurados en su vida útil, podría simplificarse el proceso de fabricación hacia la reconfiguración dinámica, aprovechando las fuentes renovables para disminuir el consumo energético y hacer una tecnología más sostenible en términos generales durante todas las etapas de la vida útil del sistema. Además, este soportaría las reparaciones, mantenimiento regenerativo y optimización en operación. A partir de la generalización del modelo desarrollado (conjunto de ecuaciones de generación de patrón fractal), se obtiene como resultado una librería en VHDL para la configuración de componentes del esquema LFSR, componentes básicos

y la red neuronal de modelado inteligente, destacando que el modelo ha sido diseñado de forma parametrizable para los diferentes niveles de la composición fractal (Ver Tabla 7).

Estos códigos permiten implementar funciones descritas en el modelo LFSR de manera eficiente con capacidad de reconfiguración dinámica para la definición del comportamiento del panel fotovoltaico a través de software Software Defined Photovoltaic (SDPV).

En este punto, surge el concepto tecnológico de extrapolar los avances en sistemas de potencia reconfigurables (Sandoval, 2019c) Smart Grid y los dispositivos electrónicos inteligentes IED (del inglés Intelligent Electronic Devices) para avanzar en el desarrollo de tecnologías de modelo circular en el área de fotovoltaica y fotovoltaica de alta concentración sin necesidad de desmontar los arreglos fotovoltaicos para adaptar los cambios que conlleven una mayor eficiencia del sistema solar instalado. Este último aspecto resulta valioso en el área de costos y versatilidad. El estudio práctico está orientado a los códigos de soporte de los dispositivos electrónicos en tanto el enfoque teórico esté dirigido al concepto tecnológico y las ecuaciones del modelo generalizado para fotovoltaica-LFSR.

\subsection{PVIDs - Dispositivos Fotovoltaicos Inteligentes}

Sandoval (2018a) desarrolló el estudio de los dispositivos electrónicos inteligentes IED aplicados a energías renovables ERNC. En este caso se plantea para aplicaciones fotovoltaicas de manera específica en la que se puede avanzar con la reconfiguración de estructuras, ampliando los concentos de electrónica a hardware de paneles fotovoltaicos inteligentes. En el caso de SFV, se plantea el modelado inteligente a nivel de definición de capas del arreglo PV al igual que la topología de la matriz de conexiones del sistema, con el objetivo de tener la configuración óptima e implementar controladores electrónicos adaptativos en una ANN. 


\subsection{Optimización del rendimiento de célula fotovoltaica}

En términos de eficiencia, la Fractal LFSR-PV tendría la capacidad de optimizar el material y la conductividad. Asimismo, el diseño propone una matriz reconfigurable para estructuras y materiales ópticos, fotocatalizador, semiconductores, fotovoltaicas y almacenamiento, como una reserva base que puede ser configurada y ponderada a través del modelado dinámico. Finalmente, es un modelo reciclable con diseño modular para ser clasificado en componentes luego de su vida útil. Esto muestra un ahorro significativo en recursos y un aumento de la eficiencia. Por su parte, las tecnologías Grätzel DSSC, Perovskita, nanoestructuras (de orden $<300 \mathrm{~nm}$ que tienen entre sus objetivos reducir la reflexión en la superficie y mejorar la absorción en el semiconductor) y PERC aportan alternativas para mejorar la eficiencia de las celdas fotovoltaicas (aumentar la captación de fotones en el espectro óptico de luz visible y la captación de electrones en la etapa de conversión), disminuir los requerimientos de energía y reducir los costos en etapa de fabricación. La contribución del presente trabajo con respecto a los antecedentes considerados es el concepto de tecnología reconfigurable: configuraciones de capas funcionales para la optimización de las celdas fotovoltaicas aplicando FPGA para la implementación del control neuronal. Esto a su vez permite la configuración de las capas del panel. Se propone una batería de materiales para la configuración de capas a partir de formulaciones de la red neuronal. La estimación de eficiencia de estos y su capacidad de adaptación permitirá alcanzar diseños óptimos por medio de la reconfiguración de la estructura y la composición de las capas del panel según las condiciones ambientales de irradiancia y temperatura.

En la Tabla 8 se presenta el reporte de optimización para factores de seguimiento solar en el arreglo fotovoltaico, técnicas de concentración solar para tecnología High Concentration Photovoltaic (HCPV), almacenamiento y recursos hardware de la ANN.

Los resultados permiten validar las preguntas de investigación a través de la correspondencia entre los elementos estructurales LFSR y la aplicabilidad de tecnología FPGA para hardware reconfigurable en donde se pueden optimizar los coeficientes de temperatura en el contexto del análisis de las tecnologías emergentes en fotovoltaica. Esto ha permitido formular un modelo en componentes fractales para fotovoltaica inteligente como una contribución en esta área de investigación. La correspondencia entre los arreglos FV reconfigurables y concentradores ópticos (CSL), arreglos de heliostatos como el proyecto cometa solar (Sandoval, 2020a), puede ser extrapolada en materiales funcionalizados para la configuración de capas en el convertidor FV a partir de una matriz predefinida de elementos semiconductores. Con base al estudio, se plantean trabajos futuros de aplicación de síntesis dinámica, FV robótica, bio-entrenamiento de ANN Fractal (Sandoval, 2020b), así como nanoestructuras para formulación adaptativa. Existen diversas alternativas basadas en el modelo LFSR: (1) diseño e implementación por fabricación aditiva in situ, (2) optimización de paneles instalados con capa de pre-emisión y capa de aislamiento para realimentación con acondicionamiento del arreglo, (3) mosaico de paneles de semiconductores y paneles bio-fotovoltaicos para remediación ambiental y compensación de emisiones de $\mathrm{CO}_{2}$. En todos los casos, los coeficientes de conversión, el almacenamiento de energía en sus diferentes estados y el desplazamiento por capas o multiplexado

y realimentación estandarizan el comportamiento matemático del arreglo. El modelo desarrollado 


\section{Tabla 8. Factores y Sistemas de Optimización del Sistema Fotovoltaico}

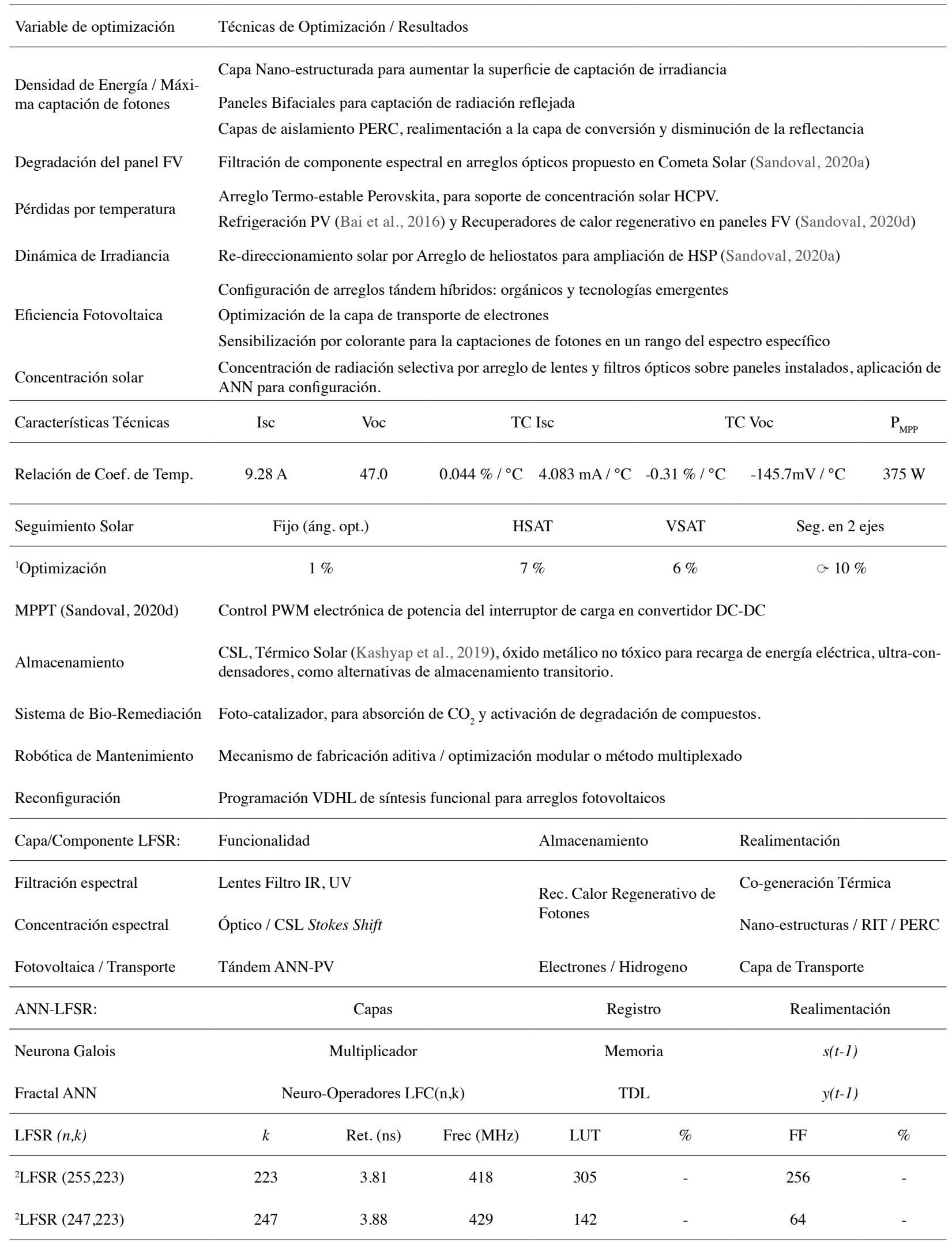

${ }^{1}$ Simulación de Eficiencia. Explorador Solar (Universidad de Chile, 2020)

${ }^{2}$ Síntesis en Hardware a través de herramienta de desarrollo ISE11.1, Xilinx 
soporta tanto diseño de capas funcionales como actualización a través de etapas adaptadas en SFV instalados en tanto que los recursos de hardware en electrónica FPGA puedan ser estimados con las ecuaciones presentadas en Sandoval (2019b).

El modelo desarrollado también puede ser orientado a aplicaciones ambientales como etapas previas de arreglos heliostáticos de redireccionamiento o canalización de radiación solar a cierta altura. Estos pueden optimizar las horas de sol pico para instalaciones FV, concentración y filtrado inteligente de forma coordinada por la ANN con el fin de alcanzar la protección de la radiación solar directa en glaciares o áreas forestales. Esto a través de tecnología de lentes fotocromáticas o polarizados tándem, filtrado espectral selectivo de radiación (UV), así como electroquímica fotosintética para procesamiento de $\mathrm{CO}_{2}$, disminución del consumo de energía, recursos y control RCR para cogeneración térmica. En el caso de los registros de energía, se consideran concentrados luminiscentes CSL, guía de onda para transmisión de energía solar (captación aérea puntos de absorción y conversión fotovoltaica en una estación terrena), con el fin de implementar el sistema con menor cantidad de material fotovoltaico, optimizando la superficie y la densidad energética de la tecnología fotovoltaica y los recuperadores de calor en el sistema de refrigeración de los paneles solares. Esto provocaría un aumento de eficiencia relacionado a los coeficientes de temperatura y recaptación. Asimismo, se incorporaría nanocircuitos de recuperación de calor, lo que del panel configurable permitiría el aprovechamiento de la energía térmica (en materiales termoeléctricos) y evitaría la disipación de calor residual al ambiente.

El control de cada una de las variables de optimización se ha diseñado a través de redes neuronales Fractal-ANN. Los aspectos a destacar corresponden al diseño estructurado en concatenación de aportes en la suma de coeficientes por etapa y diseño regenerativo: capas recaptadoras y recuperadoras, con realimentación de energía y aplicación de técnicas para micro almacenamiento en niveles intermedios (RCR) dadas las propiedades del material. Esto se suma a los aportes de eficiencia del diseño para mejorar la densidad energética de los SFV. Se han identificado microsistemas fractales en los componentes que se concatenan de forma modular, lo que permite soportar propuestas avanzadas de reparación de estructuras, activación selectiva de etapas configurables y la foto-modulación de materiales dentro del concepto Systems on Chip (SoC), aplicado a fotovoltaica.

\section{CONCLUSIONES}

Gracias al modelo matemático desarrollado para la descripción de arreglos fotovoltaicos, basado en la arquitectura LFSR, se logró un concepto tecnológico de paneles fotovoltaicos reconfigurables con capacidad evolutiva para la adaptación de parámetros, matriz de conmutación, propiedades de las capas funcionales y optimización de eficiencia. Todas estas son aplicables en una fotovoltaica distribuida para la reducción en las pérdidas asociadas a transmisión. Este modelo permite la estimación de rendimiento en laboratorios o en parques solares de investigación previamente instalados. Una de las ventajas es la posibilidad de reconfigurar el diseño según la localización del arreglo solar, por ejemplo en Smart City (Sandoval, 2018c) o plataformas de energías renovables (Sandoval, 2019a). También da la oportunidad de avanzar en instalaciones PV flotantes (con 
refrigeración por agua) como paneles solares aéreos con conversión eólica basada en cometas solares (Sandoval, 2020a), donde se optimizan condiciones como la masa de aire, irradiancia directa, efectos de reflexión y temperatura.

De esta manera, se obtiene un modelo matemático (descrito por funciones iterativas de geometría fractal) para la configuración de paneles fotovoltaicos que busca alternativas más eficientes de producción de energía y respetuosas con el medio ambiente. A partir del modelo LFSR se obtiene una generalización que permite simplificar el proceso de producción, dotando a la nueva tecnología de flexibilidad por contar con una matriz configurable de componentes del convertidor. Hasta el momento no se han presentado conceptos de paneles fotovoltaicos reconfigurables. Este modelo aportaría capacidad de adaptación y un desarrollo más sostenible en esta tecnología dentro de los criterios de hardware circular que permitan la actualización en el tiempo.

Integrando convertidores de ERNC en un sistema reconfigurable, se plantea escalar módulos piloto de convertidores de energía solar híbrida (Sandoval, 2013) de concentración fotovoltaica HCPV y Termo-Solar, basado en la propuesta para formación e investigación de nuevas tecnologías para disminuir la cantidad de material fotovoltaico, aumentar la eficiencia del sistema, disminuir los costos de implementación y aplicar re-captadores y RCR en realimentación. Esto, a su vez, considera los ciclos regenerativos y estima el impacto ambiental con reciclaje de componentes para disminuir la extracción de recursos, protegiendo ambientes naturales, agrícolas y forestales. Otros trabajos que representan posibles alternativas para los diseños de arreglos fotovoltaicos corresponden a la aplicación de mecanismos de absorción en electromagnetismo (Kaur, Upadhyaya \& Palandoken, 2018), así como algoritmos adaptativos donde se replican avances en el área de diseño de antenas inteligentes de telecomunicaciones y beamforming (Castellanos, Sandoval \& Azpúrua, 2014) para avanzar en los patrones fractales del modelo de implementación.

Se ha desarrollado un concepto tecnológico para arreglos fotovoltaicos extrapolable a otros sistemas de energías renovables, en los que se conjuga los principios de sostenibilidad y aporte al medio ambiente. Estos proyectos deben integrar funciones de protección ambiental, compensación, bioremediación y reservas ecológicas. Se propone así una plataforma para el estudio de la eficiencia y soluciones óptimas en la matriz energética bajo un modelo de redes auto-organizadas con esquema fractal, así como la digitalización aplicando modelos neuronales para la gestión remota de las instalaciones, la adaptación de los parámetros de los convertidores y el control adaptativo. El concepto de tele reconfiguración a través de tecnología FPGA permitirá optimizar la estructura de los convertidores, su concatenación modular, rendimiento y función objetivo como sistemas eco-inteligentes. Asimismo, los códigos en lenguaje descriptor de hardware VHDL desarrollados representan un aporte para la implementación en línea de soluciones innovadoras en el campo de la ingeniería de la energía solar-fotovoltaica. La ingeniería debe considerar el diseño de sistemas regenerativos que se inspire en esa renovación de los recursos y energía dentro de un equilibrio y conservación, tomando en cuenta la electrónica reconfigurable, los modelos circulares y la matriz adaptativa de celdas solares. 


\section{REFERENCIAS}

Alarcón, D., Montilla, M., Montilla, X., Montilla, L., Ortiz, R., \& Marquez, K. (2014). Síntesis Electroquímica del Semiconductor $\mathrm{Cu} 2 \mathrm{Se}$ en Presencia de iones $\mathrm{Pb} 2+$ sobre Carbón Vítreo. Conocimiento Libre y Licenciamiento CLIC, (8).

Almonacid, F., Fernández, E. F., Rodrigo, P., Pérez-Higueras, P. J., \& Rus-Casas, C. (2013). Estimating the maximum power of a high concentrator photovoltaic (HCPV) module using an artificial neural network. Energy, 53, $165-172$.

Amorós-Pérez, A., Cano-Casanova, L., González-González, S., Peco-García, C., Lillo-Rodenas, M. A., RománMartínez, M. C., \& Keller, N. (2019). Preparación de fotocatalizadores de $\mathrm{TiO}_{2}$ y $\mathrm{ZnO}$ para la eliminación de contaminantes en medio acuoso. Recuperado de https://rua.ua.es/dspace/bitstream/10045/96668/3/Resumen_ Ana-Amoros-Secat19.pdf

Bai, A., Popp, J., Balogh, P., Gabnai, Z., Pályi, B., Farkas, I., ...\& Zsiborács, H. (2016). Technical and economic effects of cooling of monocrystalline photovoltaic modules under Hungarian conditions. Renewable and Sustainable Energy Reviews, 60, 1086-1099.

Bernechea, M., Miller, C., Xercavins, G., So, D., Stavrinadis, A., Konstan, G. (2016). Solution-processed cells based environmentally friendly AgBiS2 nanocrystals. Nature Photonics, 10, 521-525. DOI: 10.1038/ NPHOTON.2016.108

Camargo-Silva, S. M., Muñoz-Prieto, E., Vera-Graziano, R., \& Gomez-Pachón, E. Y. (2017). Fabricación de nanofibras $\mathrm{de}_{\mathrm{TiO}_{2}} / \mathrm{ZnO}$ para aplicaciones de almacenamiento de energía. Orinoquia, 21(1), 56-63. Recuperado de https:// www.redalyc.org/pdf/896/89659219002.pdf

Castellanos Hernández, J. A., Sandoval Ruiz, C. E., \& Azpúrua Auyanet, M. A. (2014). A FPGA implementation of a LMS adaptative algorithm for smart antenna arrays. Revista Técnica de la Facultad de Ingeniería Universidad del Zulia, 37(3), 270-278.

Cereceda, S. B. (2018). Materiales híbridos a base de Bi2WO6 y polímeros de Poli (N-vinilcarbazol) como capa activa absorbente en la región visible para la generación de fotocorriente (Tesis de Maestría). Recuperado de https://cimav.repositorioinstitucional.mx/jspui/bitstream/1004/2284/1/Tesis\%20M.\%20Sof\%C3\%ADa\%20 Basurto\%20Cereceda.pdf

Cevik, E., Tombuloglu, H., Anıl, I., Senel, M., Sabit, H., AbdulAzeez, S., ... \& Barghouthi, M. (2020). Direct electricity production from Microalgae Choricystis sp. and investigation of the boron to enhance the electrogenic activity. International Journal of Hydrogen Energy, 45(19), 11330-11340.

Choi, J., Choi, M. J., Kim, J., Dinic, F., Todorovic, P., Sun, B., ... \& Voznyy, O. (2020). Stabilizing Surface Passivation Enables Stable Operation of Colloidal Quantum Dot Photovoltaic Devices at Maximum Power Point in an Air Ambient. Advanced Materials, 32(7), 1906497.

Díaz-García, A. K. (2017). Células tándem fotoelectroquímicas para la generación de hidrógeno y otros combustibles solares (Tesis). Universidad de Alicante. Recuperado de https://dialnet.unirioja.es/servlet/tesis?codigo=136199

Einzinger, M., Wu, T., Kompalla, J. F., Smith, H. L., Perkinson, C. F., Nienhaus, L., ... \& Baldo, M. A. (2019). Sensitization of silicon by singlet exciton fission in tetracene. Nature, 571(7763), 90. Recuperado de https:// www.nature.com/articles/d41586-019-02014-8

ESA. (2020). Bendy, ultra-thin solar cell. Recuperado de https://www.esa.int/

Fernández-Ahumada, L. M., Ramírez-Faz, J., López-Luque, R., Varo-Martínez, M., Moreno-García, I. M., \& de la Torre, F. C. (2020). A novel backtracking approach for two-axis solar PV tracking plants. Renewable Energy, 145, 1214-1221. Recuperado de https://www.sciencedirect.com/science/article/pii/S0960148119308900

Flores Díaz, N. (2014). Determinación de la eficiencia energética de celdas solares sensibilizadas con pigmentos obtenidos de extractos naturales, procesos microbiológicos y nanopartículas de germanio (Tesis de Licenciatura). Universidad de Costa Rica. Recuperado de http://repositorio.sibdi.ucr.ac.cr:8080/jspui/handle/123456789/1745

Formentín Vallés, R. (2013). Estudio de las características electrónicas de dispositivos fotovoltaicos moleculares: células Grätzel (Tesis de Doctorado). Universidad Politécnica de Valencia. Recuperado de https://riunet.upv. es/bitstream/handle/10251/36015/MEMORIA.pdf?sequence=1 
González de la Fuente, J. (2015). Utilización de ultracondensadores para la mejora de eficiencia de una instalación fotovoltaica (Tesis de Doctorado). Universidad de Valladolid. Recuperado de https://pdfs.semanticscholar.org/ e1bf/de0a4cca5c6ccef41fba24efb9a566b64616.pdf

Gutiérrez, D. F. G., Quijano, D. G., Gutiérrez, D. I. G., \& Cervantes, E. S. (2018). Celdas solares tipo perovskita y su estabilidad en el medio ambiente. Ingenierías, 21(80), 21-35.

Hassan, A., Wahab, A., Qasim, M. A., Janjua, M. M., Ali, M. A., Ali, H. M., ... \& Javaid, N. (2020). Thermal management and uniform temperature regulation of photovoltaic modules using hybrid phase change materials-nanofluids system. Renewable Energy, 145, 282-293.

Kashyap, V., Sakunkaewkasem, S., Jafari, P., Nazari, M., Eslami, B., Nazifi, S., ... \& Ghasemi, H. (2019). Full Spectrum Solar Thermal Energy Harvesting and Storage by a Molecular and Phase-Change Hybrid Material. Joule, 3(12), 3100-3111.

Kaur, K. P., Upadhyaya, T., \& Palandoken, M. (2018). Dual-Band Compact Metamaterial-Inspired Absorber with Wide Incidence Angle and Polarization Insensitivity for GSM and ISM Band Applications. Radioengineering, 27(4), 1025-1031. Recuperado de https://www.radioeng.cz/fulltexts/2018/18_04_1025_1031.pdf

Khalaji, M., Bakhodaa, S., Saidurbc, R. and Hanaeia, H. (2018). Recent progress in perovskite solar cells. Renewable and Sustainable Energy Reviews, 81(2), 2812-2822.

Kim, H., Parkhideh, B., Bongers, T. D., \& Gao, H. (2012). Reconfigurable solar converter: A single-stage power conversion PV-battery system. IEEE transactions on power electronics, 28(8), 3788-3797. Recuperado de http:// www.pgembeddedsystems.com/securelogin/upload/project/IEEE/41/PG2013PE0010/19.pdf

Kim, K. A., Xu, C., Jin, L., \& Krein, P. T. (2013). A dynamic photovoltaic model incorporating capacitive and reversebias characteristics. IEEE Journal of photovoltaics, 3(4), 1334-1341. Recuperado de http://www.ematlab.com/ paper/dynamic/D25/D25.pdf

Li, X., Dar, M. I., Yi, C., Luo, J., Tschumi, M., Zakeeruddin, S. M., ... \& Grätzel, M. (2015). Improved performance and stability of perovskite solar cells by crystal crosslinking with alkylphosphonic acid $\omega$-ammonium chlorides. Nature chemistry, 7(9), 703.

Madriz, L., Tatá, J., Cuartas, V., Cuéllar, A., \& Vargas, R. (2014). Photoelectrochemical solar cells based on Bi2WO6. Química Nova, 37(2), 226-231. Recuperado de http://www.scielo.br/pdf/qn/v37n2/v37n2a06.pdf

Martínez, J. L. O., Gallardo, S. G. F., \& Ríos, A. V. (2016). Diseño de celdas solares sensibilizadas con tinta N719 empleando electrolitos en gel de red polimérica interpenetrada, a base de poli (anilina-co-o-fenilendiamina) $o$ polianilina dopados con i-carragenina (Tesis). Recuperado de https://cimav.repositorioinstitucional.mx/jspui/ bitstream/1004/850/1/Jorge\%20Luis\%20Olmedo\%20Mart\%C3\%ADnez\%20MCM.pdf

Navarro Vásquez, A. P. (2015). Los Carotenoides y su aplicación en la Biotecnología Ambiental (Tesis de Bachillerato). Pontificia Universidad Católica del Ecuador. Recuperado de http://repositorio.puce.edu .ec/handle/22000/8730

Nishigaki, Y., Nagai, T., Nishiwaki, M., Aizawa, T., Kozawa, M., Hanzawa, K., ... \& Fujiwara, H. (2020). Extraordinary Strong Band-Edge Absorption in Distorted Chalcogenide Perovskites. Solar RRL, 1900555. Recuperado de https://onlinelibrary.wiley.com/doi/abs/10.1002/solr.201900555

NREL. (2020). Best Research-Cell Efficiency Chart. Recuperado de https://www.nrel.gov/pv/cell-efficiency.html

Pankratov, D., Pankratova, G., \& Gorton, L. (2020). Current Trends in Development of Photosynthetic Bioelectrochemical Systems for Light Energy Conversion. In Novel Catalyst Materials for Bioelectrochemical Systems: Fundamentals and Applications (pp. 123-146). American Chemical Society.

Pérez, S., Yasmin, G., Gómez, J. A., \& Vera López, E. (2018). Energía renovable: celdas solares de Perovskita. Investigación Joven, 5.

Reyes-Tolosa, M.D. (2012). Modelo de nucleación y crecimiento de capas nanoestructuradas de óxido de zinc sobre sustratos cerámicos con aplicación a materiales fotovoltaicos híbridos (Tesis de Doctorado). Recuperado de https://riunet.upv.es/bitstream/handle/10251/14725/tesisUPV3759.pdf?sequence=1

Ruiz, P. R. (2014). Diseño y caracterización de nuevos sistemas fluorescentes para su utilización como interruptores y puertas lógicas moleculares: implicación de procesos de transferencia electrónica y de energía en el estado 
excitado (Tesis de Doctorado). Universidad de Huelva. Recuperado de https://dialnet.unirioja.es/servlet/ tesis? codigo $=46664$

Sandoval-Ruiz, C. (2020a). Proyecto Cometa Solar - CS para optimización de Sistema Fotovoltaicos. Universidad, Ciencia y Tecnología, 24(100).

Sandoval-Ruiz, C. E. (2020b). LFSR-Fractal ANN Model applied in R-IEDs for Smart Energy. IEEE Latin America Transactions, 18(4), 677-686. Recuperado de https://www.inaoep.mx/ IEEElat/index.php/transactions/article/ view/1423/446

Sandoval-Ruiz, C. (2020c). Operador matemático $\operatorname{LFC}(\mathrm{n}, \mathrm{k})$ en campos finitos basado en concatenación fractal para GF(2m) - Extendido. Ciencia e Ingeniería, 41(2), 197-204. Recuperado de http://erevistas.saber.ula.ve/index. $\mathrm{php} / \mathrm{cienciaeingenieria/article/view/16055/21921927185}$

Sandoval-Ruiz. C. (2020d). Arreglo Inteligente de Concentración Solar FV para MPPT usando Tecnología FPGA. Revista Técnica Univerdidad del Zulia, 43.

Sandoval-Ruiz, C. (2019a). Modelo VHDL de Control Neuronal sobre tecnología FPGA orientado a Aplicaciones Sostenible, Revista Chilena de ingeniería. Ingeniare, 27(3). 383-395 Recuperado de https://dialnet.unirioja.es/ servlet/articulo?codigo $=6841589$

Sandoval-Ruiz, C. (2019b). Métodos numéricos en diferencias finitas para la estimación de recursos de Hardware FPGA en arquitecturas LFSR (n,k) fractales. Ingeniería, investigación y tecnología, 20(3). 1-10. http://dx.doi. org/10.22201/fi.25940732e.2019.20n3.032

Sandoval-Ruiz, C. (2019c). Plataforma de Investigación de Redes Eléctricas Reconfigurables de Energías Renovables aplicando Modelos LFSR. Universidad, Ciencia y Tecnología, 23(95), 103-115. Recuperado de http://uctunexpo. autanabooks.com/index.php/uct/article/view/253/409

Sandoval-Ruiz, C. (2018a). Códigos Reed Solomon para sistemas distribuidos de energías renovables y smart grids a través de dispositivos electrónicos inteligentes sobre tecnología FPGA. Memoria Investigaciones en Ingeniería, (16), 37-54. Recuperado de http://revistas.um.edu.uy/index.php/ingenieria/article/view/296

Sandoval-Ruiz,C. (2018b). Control de Micro-Redes de Energía Renovable a través de estructuras LFCS Reconfigurables en VHDL. Ciencia y tecnología, (18), 71-86. https://doi.org/10.18682/cyt.v1i18.847

Sandoval-Ruíz, C. (2018c). Arquitectura Reconfigurable y Redes Inteligentes aplicadas al Diseño Sostenible en Smart City. Revista Electrónica Científica Perspectiva, 7(12), 1-19.

Sandoval-Ruiz, C. (2016). Plataforma de Gestión, Investigación y Formación en Tecnologías Sostenibles, para soporte de un Laboratorio Remoto. Rev. Eduweb, Univ. Carabobo, 10(1), 79-92. Recuperado de https://dialnet.unirioja. es/servlet/articulo?codigo $=5906476$

Sandoval Ruiz, C. (2013). Diseño conceptual de un módulo híbrido para Generación eléctrica. En VIII Congreso Nacional y 2do Congreso Internacional de Investigación Universidad de Carabobo.

Sandoval-Ruiz, C. (2012). Codificador RS (n, k) basado en LFCS: caso de estudio RS (7, 3). Revista Facultad de Ingeniería, (64), 68-78. Recuperado de http://aprendeenlinea.udea.edu.co/revistas/index.php/ingenieria/article/ view/13116

Valero-Moro, J., Bonilla-Turmero, Y., \& Sandoval-Ruiz, C. (2017). Estación tele-operada de robótica móvil, para el laboratorio de micro-controladores. Universidad Ciencia y Tecnología, 21(83), 69-75. Recuperado de http:// www.uct.unexpo.edu.ve/index.php/uct/article/viewFile/794/639

Universidad de Chile (2020). Explorador Solar Fotovoltaico. Recuperado de http://ernc.dgf.uchile.cl:48080/fotovoltaico

Valero Delgado, A. (2019). ¿Economía circular? El reto de la reciclabilidad de los nuevos materiales. DIGITAL.CSIC. Recuperado de https://digital.csic.es/handle/10261/176770

Venneri, F., Costanzo, S., \& Borgia, A. (2019). A Dual-Band Compact Metamaterial Absorber with Fractal Geometry. Electronics, 8(8), 879. Recuperado de https://www.mdpi.com/2079-9292/8/8/879

Xu, Y., Gong, T., \& Munday, J. N. (2015). The generalized Shockley-Queisser limit for nanostructured solar cells. Scientific reports, 5, 13536.

Young, J. L., Steiner, M. A., Döscher, H., France, R. M., Turner, J. A., \& Deutsch, T. G. (2017). Direct solar-to-hydrogen conversion via inverted metamorphic multi-junction semiconductor architectures. Nature Energy, 2(4), 1-8. 